\title{
Designing Paclitaxel Drug Delivery Systems Aimed at Improved Patient Outcomes: Current Status and Challenges
}

\author{
Madhu S. Surapaneni, ${ }^{1}$ Sudip K. Das, ${ }^{2}$ and Nandita G. Das ${ }^{2}$ \\ ${ }^{1}$ College of Pharmacy, Idaho State University, Pocatello, ID 83201, USA \\ ${ }^{2}$ Department of Pharmaceutical Sciences, Butler University, Indianapolis, IN 46208, USA
}

Correspondence should be addressed to Nandita G. Das, ndas@butler.edu

Received 3 April 2012; Accepted 29 April 2012

Academic Editors: G. A. Gudelsky, T. Irie, J.-A. Mico, and B.-N. Wu

Copyright (C) 2012 Madhu S. Surapaneni et al. This is an open access article distributed under the Creative Commons Attribution License, which permits unrestricted use, distribution, and reproduction in any medium, provided the original work is properly cited.

\begin{abstract}
Paclitaxel is one of the most widely used and effective antineoplastic agents derived from natural sources. It has a wide spectrum of antitumor activity, particularly against ovarian cancer, breast cancer, nonsmall cell lung cancer, head and neck tumors, Kaposi's sarcoma, and urologic malignancies. It is a highly lipophilic compound with a log P value of 3.96 and very poor aqueous solubility of less than $0.01 \mathrm{mg} / \mathrm{mL}$. In addition, the compound lacks functional groups that are ionizable which could potentially lead to an increase in its solubility with the alteration in $\mathrm{pH}$. Therefore, the delivery of paclitaxel is associated with substantial challenges. Until the introduction of Abraxane, only commercial formulation was solution of paclitaxel in cremophor, which caused severe side effects. However, in recent years, a number of approaches have been reported to solubilize paclitaxel using cosolvents and inclusion complexes. In addition, innovative approaches have been reported for passive targeting of tumors using nanoparticles, nanosuspensions, liposomes, emulsions, micelles, implants, pastes and gels. All approaches for delivery of improved therapeutic outcome have been discussed in this paper.
\end{abstract}

\section{Introduction}

Paclitaxel (Taxol) is one of the most widely used and effective antineoplastic agents derived from natural sources. It is a pseudoalkaloid that has a taxane ring as its nucleus $\left(\mathrm{C}_{47} \mathrm{H}_{51} \mathrm{NO}_{14}, \mathrm{MW}\right.$ 853.93) [1] (Figure 1). Its identification was the result of screening 35,000 plant species for antitumor activity by the U.S. National Cancer Institute (NCI) in 1958. In 1963, Dr. Monroe Wall and Dr. M. C. Wani of Research Triangle Institute, North Carolina, demonstrated that the extract of the inner bark of Pacific Yew (Taxus brevifolia, family: Taxaceae) had antitumor activity. Although the pure form of the drug was isolated in 1969, it was not until 1971 that it was identified as paclitaxel and the structure published [2]. Paclitaxel has a wide spectrum of antitumor activity, particularly against ovarian cancer, breast cancer, nonsmall cell lung cancer, head and neck tumors, Kaposi's sarcoma, and urologic malignancies [3]. For instance, researchers at the Johns Hopkins Oncology Center have reported a 30\% response rate in patients with advanced ovarian cancer and who were previously treated with high dose chemotherapy $[4,5]$. The response rate in patients with metastatic breast cancer was found to be $56 \%[4,6]$.

In contrast to the nuclear mechanism of action of a majority of other cytotoxic drugs, which act by attacking the nuclear components such as DNA and RNA, paclitaxel acts by a unique mechanism of action. The main site of action of paclitaxel is the microtubules; however, unlike the vinca alkaloids, which induce depolymerization of the microtubules, paclitaxel acts during the mitotic phase of cell division and promotes the polymerization of the tubulin proteins and their assembly, thereby stabilizing the microtubules and making them dysfunctional while arresting cell growth [7]. It has been shown that paclitaxel inhibits angiogenesisrelated cell migration, proliferation, and collagenase secretion [8]. The combination of both the antiangiogenic and cytotoxic properties contributes to paclitaxel's efficacy as an anticancer agent [9]. In spite of the remarkable prospect of paclitaxel as an antitumor drug, it is difficult to formulate owing to its extreme lipophilic nature. The formulation and 


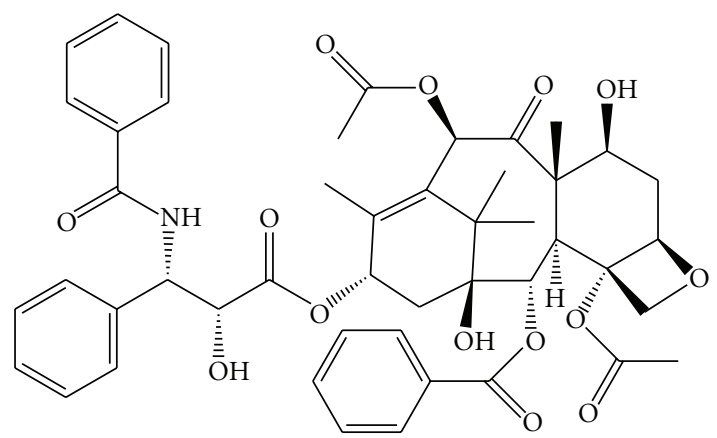

Figure 1: Structure of Paclitaxel $(2 \alpha, 4 \alpha, 5 \beta, 7 \beta, 10 \beta, 13 \alpha)-4,10$-bis(acetyloxy)-13-\{[(2R,3S)-3-(benzoylamino)-2-hydroxy-3-phenylpropanoyl] oxy\}-1,7-dihydroxy-9-oxo-5,20-epoxytax-11-en-2-yl benzoate.

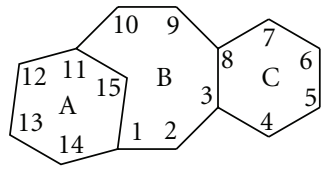

FIgURe 2: Taxane ring.

clinical problems related to paclitaxel's solubility, toxicity, and development of drug resistance have led to innovative research leading to the development of alternative dosage forms that can overcome the above-mentioned problems. This paper intends to discuss the challenges and various related aspects of the formulation of paclitaxel.

\section{The Paclitaxel Molecule and Its Delivery Challenges}

Extraction of paclitaxel from its natural source, Taxus brevifolia, causes the death of several plants to yield a few grams of the drug, which is not a practical option. A completely synthetic method of production of paclitaxel has not yet been developed due to the challenges presented by its structural complexity [10-12]. Current industrial production of paclitaxel is done by plant cell fermentation technology, whereby paclitaxel is extracted from a cultured Taxus cell line and purified by chromatography.

Paclitaxel is a diterpenoid centered around a bulky, complex, and fused taxane ring (Figure 2) composed of a number of hydrophobic substituents, which makes it a highly lipophilic compound with a $\log P$ value of approximately 4 and aqueous solubility of less than $0.01 \mathrm{mg} / \mathrm{mL}$ [13-15]. The compound lacks potentially ionizable functional groups which could lead to an increase in its solubility with alteration in $\mathrm{pH}$. Among nonaqueous solvents, the solubility is found to be $\sim 46 \mathrm{mM}$ in ethanol, $\sim 20 \mathrm{mM}$ in methylene chloride or acetonitrile, and $\sim 14 \mathrm{mM}$ in isopropanol. It is also soluble in methanol, tertiary-butanol, and dimethyl sulfoxide $[4,16]$.

The common approaches to increase aqueous solubility, such as formation of salts and addition of charged complexing agents, are not feasible options for paclitaxel [17]. Synthesis of prodrugs to improve the aqueous solubility of paclitaxel has been attempted. The $2^{\prime}$ position on the structure of paclitaxel may be the ideal position for the insertion of functional groups to create prodrugs of paclitaxel, because several derivatives of 2 -acyl-paclitaxel can quickly hydrolyze back into paclitaxel in the blood [18]. A C-7 prodrug ester of paclitaxel has also been prepared because the arrangement of the C-7 hydroxyl group does not appear to be a factor in influencing cytotoxicity [19]. A paclitaxel ester in the presence of a strong electron withdrawing substituent, like an alkoxy group in the $\alpha$-position of the ester, was synthesized by Nicolaou et al., to facilitate the quickening of the hydrolytic cleavage [20]. These prodrugs have shown cytotoxic activity comparable to paclitaxel against cancer cell lines in vitro. Prodrugs of paclitaxel formulated using PEG has been a promising approach because PEG imparts superior aqueous solubility $[21,22]$. Nevertheless, the pursuit of designing prodrugs of paclitaxel remains primarily academic, as industrial efforts have focused on the design of water soluble derivatives or structural analogues of paclitaxel.

\section{Commercially Available Dosage Forms of Paclitaxel}

The formulation of paclitaxel most widely used in the clinical setting is the solubilized form of the drug (brand and generic), which is diluted before intravenous administration. The formulation contains polyoxyethylated castor oil (Cremophor EL) in a $1: 1 \mathrm{v} / \mathrm{v}$ mixture with dehydrated ethanol, a powerful solubilizer combo. It remains stable in unopened vials for 5 years at $4^{\circ} \mathrm{C}$ [4]. Polyoxyethylated castor oil is also used in the formulation of various other hydrophobic anticancer agents such as teniposide, echinomycin, and didemnin B [23]. However, this excipient is associated with side effects such as bronchospasms, hypotension, and symptoms of hypersensitivity [24, 25]. The constituents of polyoxyethylated castor oil can induce histamine release and cause hypotension and hypersensitivity reactions following rapid administration of the infusion or as a result of an IV bolus administration [26, 27]. Therefore, paclitaxel formulations must be slowly infused over a period of several hours to minimize the intensity and frequency of side effects. The hypersensitivity reactions were evident at almost every phase 
in development, in both preclinical and clinical testing therefore, it is recommended that patients be premedicated with corticosteroids and antihistamines prior to drug infusion to prevent or minimize the anticipated reactions $[26,28,29]$. The commercially available paclitaxel solution formulation is diluted 5-20 fold in normal saline or 5\% dextrose solution for administration as an intravenous infusion, therefore stability of the formulation after dilution is a concern. The diluted formulation results in a concentration of $0.3-$ $1.2 \mathrm{mg} / \mathrm{mL}$ of drug, which is considerably higher than the $0.01 \mathrm{mg} / \mathrm{mL}$ aqueous solubility of paclitaxel, posing the risk of drug precipitation upon dilution $[4,25]$.

\section{Nanoparticles and Nanosuspensions}

To decrease the toxic effects associated with the conventional formulation described above, and minimize the risk of precipitation of paclitaxel upon dilution, a nanoparticle formulation for paclitaxel was introduced in 2005 under the trade name Abraxane. The technology for particle formation involves a proprietary process that binds unmodified albumin to the paclitaxel molecule yielding conjugate masses of $\sim 130 \mathrm{~nm}$ size. Following infusion, these nanoparticles rapidly dissociate to yield an albumin bound drug complex. Albumin paclitaxel molecules bind to an albumin receptor (gp60) on endothelial cells which transports paclitaxel into the extravascular space via the formation caveolae [30]. An alternate transport pathway is considered to be via binding of the nanoparticles with secreted protein acidic rich in cysteine (SPARC). Since SPARC is overexpressed in many solid tumors including bladder and prostate cancers, the nab-paclitaxel leads to a 33\% increase in intratumoral concentrations and a 50\% higher dose of paclitaxel delivered compared with a conventional paclitaxel infusion. Moreover, the nab-paclitaxel being solvent free, the infusion time is much shorter compared to paclitaxel with Cremophor EL [31]. Ibrahim et al. reported on the pharmacokinetics of Abraxane, (known as ABI-007 during development) [32].

Among alternative experimental delivery systems of paclitaxel, nanoparticles of various biodegradable polymers and bioadhesive materials have been considered as promising. Nanotechnology can help to improve the bioavailability of poorly soluble drugs such as paclitaxel, enhancing drug delivery [33]. Nanoparticles also have the ability to permeate through certain tissues, adding to their drug targeting potential. They deliver the drug to the targeted tissue efficiently without clogging the capillaries while protecting the drug's bioactivity and stability $[14,34-36]$. Upon incorporation of paclitaxel into nanoparticles, there is a demonstrable enhancement in drug action due to changes in tissue distribution and pharmacokinetics [15, 37]. Additionally, it has been shown that nanoparticles can avoid rapid clearance by the reticuloendothelial system and can preferentially accumulate in solid tumors by escaping the angiogenic vasculature permeating the neoplasm [38-40]. Studies indicate that drugs delivered in nanoparticle carriers result in an extended retention of the drug in the tumors, diminution in tumor growth, and prolonged survival of the test subject $[34,41,42]$. The multidrug resistance phenotype, mediated

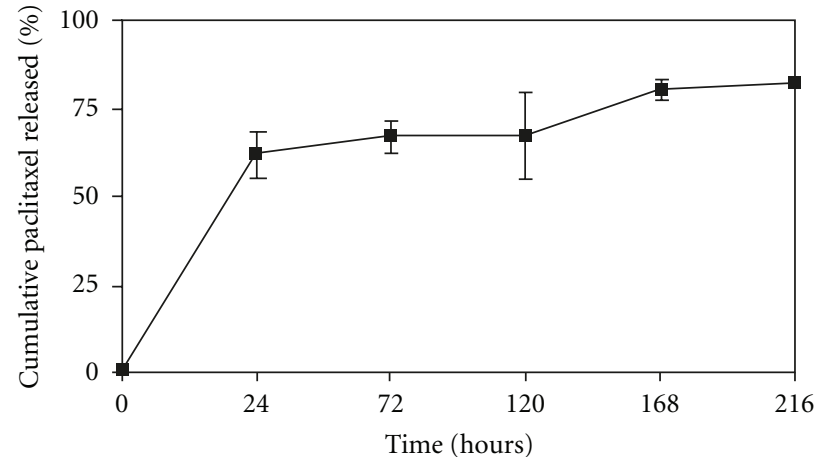

FIgUre 3: Cumulative in vitro release of paclitaxel from PLGANps (Resomer RG 502). PLGA-Nps containing paclitaxel 1\% (w/w) were diluted in $\mathrm{PBS}$, incubated at $37^{\circ} \mathrm{C}$, and shaken horizontally. At preselected time intervals, the released drug was separated by ultracentrifugation and the residual amount of paclitaxel present in the nanospheres was determined by HPLC. (reproduced with permission from Fonseca et al., [33]).

by p-glycoprotein in the tumor cells, can also be overcome by nanoparticle drug delivery. This is important because acquired resistance to paclitaxel has been reported [43-45]. An additional advantage of nanoparticles is their enhanced stability, both during storage and in biological fluids [46].

Fonseca et al. have prepared nanoparticles of paclitaxel by using the interfacial deposition method, in which they added an organic solution of PLGA and paclitaxel in acetone to an aqueous poloxamer 188 solution under magnetic stirring at room temperature, followed by washing and harvesting of nanoparticles by ultracentrifugation. The in vitro release studies were conducted by measuring the residual amount of paclitaxel at specific time points after the PLGAnanoparticles containing paclitaxel were diluted in PBS and incubated at $37^{\circ} \mathrm{C}$ in a horizontal shaker. The particles exhibited a biphasic pattern for paclitaxel release, illustrated by an early fast release during the first $24 \mathrm{hrs}$, followed by a slower and constant release (Figure 3). Two different copolymers were studied, and the in vitro antitumoral activity of the drug-loaded nanoparticles was determined by the colorimetric MTT assay after incubating the cells with paclitaxel-loaded nanoparticles for various time periods (Figure 4) [33].

$\mathrm{Mu}$ and Feng investigated the use of $\mathrm{d}$ - $\alpha$-tocopheryl polyethylene glycol 1000 succinate (vitamin E TPGS or TPGS) as a novel emulsifier and matrix material for the preparation of nanoparticles [34]. The nanoparticles loaded with paclitaxel were prepared by a modified oil-in-water single emulsion solvent evaporation/extraction technique. The size of the particles ranged from $300-1000 \mathrm{~nm}$. In vitro release from the nanoparticles was studied by suspending the drug-loaded nanoparticles in PBS and shaking the tubes horizontally. At specific time points, the tubes were centrifuged, and the supernatant was collected for analysis using HPLC. Precipitated nanoparticles were resuspended in the buffer and shaken. When different types of PLGA were used as polymers with $0.03 \mathrm{wt} \%$ TPGS as emulsifier, an initial burst 


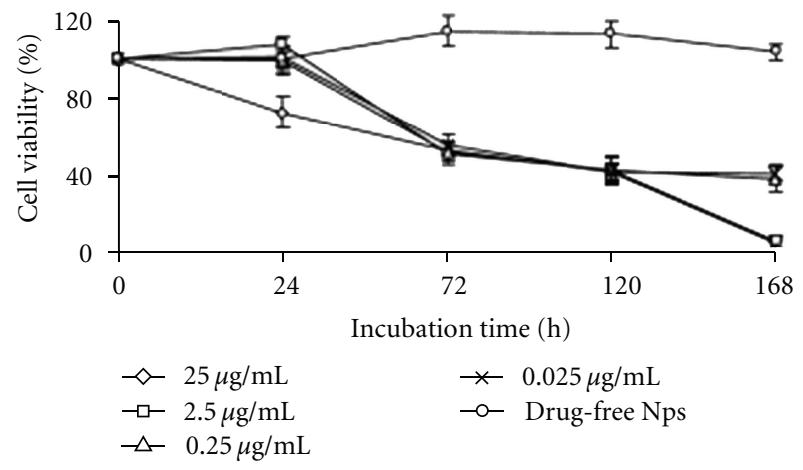

(a) RG 502

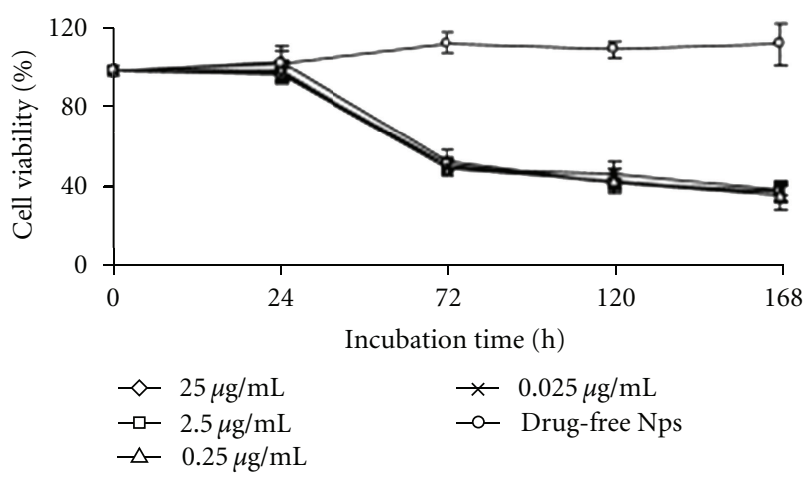

(b) RG 755

Figure 4: Viability of NCI-H69 cells incubated with drug-free Nps or Ptx-PLGA-Nps prepared with the RG 502 copolymer (a) or with RG 755 (b). Cells were seeded into 96-well plates and incubated with different concentrations of both formulations for 24, 72, 120 or $168 \mathrm{~h}$ as described (reproduced with permission from Fonseca et al., [33]).

release pattern was common to all formulations, following which the release rate dropped to generate nearly constant release of drug up to one month (Figure 5(a)) [34]. When TPGS was blended with PLGA in the nanoparticle matrix, it became more hydrophilic and resulted in an increase in drug release rate with an increasing ratio of TPGS (Figure 5(b)) [34].

Sharma et al. reported the preparation of paclitaxel containing polyvinylpyrrolidone nanoparticles crosslinked with $\mathrm{N}, \mathrm{N}$-methylene bisacrylamide (MBA) in inverse microemulsion and determined their antitumor effect in murine melanoma. The in vivo efficacy of these nanoparticles, when measured using reduction in tumor volume and increased survival time as parameters, was significantly greater compared to an equivalent concentration of free taxol [38]. SiShen and Guofeng also prepared nanoparticles of paclitaxel using freeze drying and solvent extraction/evaporation techniques. Their data indicated that short and saturated chains of phospholipids, such as dipalmitoyl-phosphatidyl-choline (DPPC), have good emulsifying effect [47].

Müller and Petes evaluated the process of high-pressure homogenization for the formulation of nanosuspensions of poorly soluble drugs [48]. Nanosuspension formulations of insoluble drugs such as paclitaxel offer the advantage of being suitable for parenteral administration. The suspension dosage form permits targeting of paclitaxel to organs like liver, spleen, lungs, and lymphatic circulation to a certain extent, by the use of particles of varying size and through administration through various routes $[4,49]$. Merisko-Liversidge et al. evaluated the process of wet milling in the formulation of a nanocrystalline suspension of poorly soluble anticancer drugs, including paclitaxel [24]. The nanoparticle formulation containing $2 \% \mathrm{w} / \mathrm{v}$ drug suspension and $1 \%$ w/v surfactant stabilizer (Pluronic F127 for paclitaxel) was wet milled on a low energy mill until a final size of less than $400 \mathrm{~nm}$ was achieved, as evaluated by photon correlation spectroscopy. These suspensions were suitable for intravenous bolus injection without any incidence of acute toxicity in vivo, and the tumor regression, expressed as the percentage of tumor weight, was significant [24].

\section{Liposome Formulations of Paclitaxel}

Liposomes are microscopic lipoid vesicles ranging from $250 \AA$ to $>20 \mu \mathrm{m}$ in diameter and offer a flexible platform to encapsulate both lipophilic and hydrophilic drugs. The lipophilic drugs incorporate in the lipid bilayer while the hydrophilic drugs locate in the vesicle cavity. Encapsulation of drugs in liposomes causes a change in their pharmacokinetic and pharmacodynamic properties, resulting in a decrease in toxicity and increase in the potency $[4,50]$. Liposomes can be used for specific targeting of cytotoxic compounds to select tissues, but they can be rapidly cleared by the mononuclear phagocytic system in the liver and spleen unless special modifications are made to the phospholipid surface [51]. The major problems associated with liposomes are their limited long-term stability and difficulty in largescale manufacturing of sterile liposomes.

Crosasso et al. have prepared and characterized sterically stabilized paclitaxel-containing liposomes. They compared conventional paclitaxel-loaded liposomes with stealth or sterically stabilized long circulating paclitaxel-containing liposomes because these liposomes can circulate in the blood for prolonged periods. The PEGylated liposomes were prepared using paclitaxel with phospholipids and cholesterol in the molar ratio of $1: 30$ (mol drug: mol lipid). The formulation containing egg yolk phosphatidylcholine (PC) and phosphatidylglycerol (PG transesterified from egg $\mathrm{PC})$ in the ratio $9: 1$ and paclitaxel and lipids in the molar ratio of $1: 30$ was found to have an incorporation efficiency of $95 \%$. This formulation retained $90 \%$ of the drug content over a study period of 2 months in the hydrated state at $4^{\circ} \mathrm{C}$, during which the liposomes were physically stable (Figure 6) [51]. Incorporation of more than 20\% of cholesterol decreased the incorporation efficiency and physical stability of the formulations. The liver and spleen distributions of the conventional and PEGylated liposomes containing paclitaxel were evaluated after extraction of paclitaxel from the tissue using $t$-butyl methyl ether (Figures $7(\mathrm{a})$ and $7(\mathrm{~b}))$ [51]. Drug uptake in liver and spleen was lower with PEGylated liposomes after 0.5 and $3 \mathrm{hrs}$ [51]. 

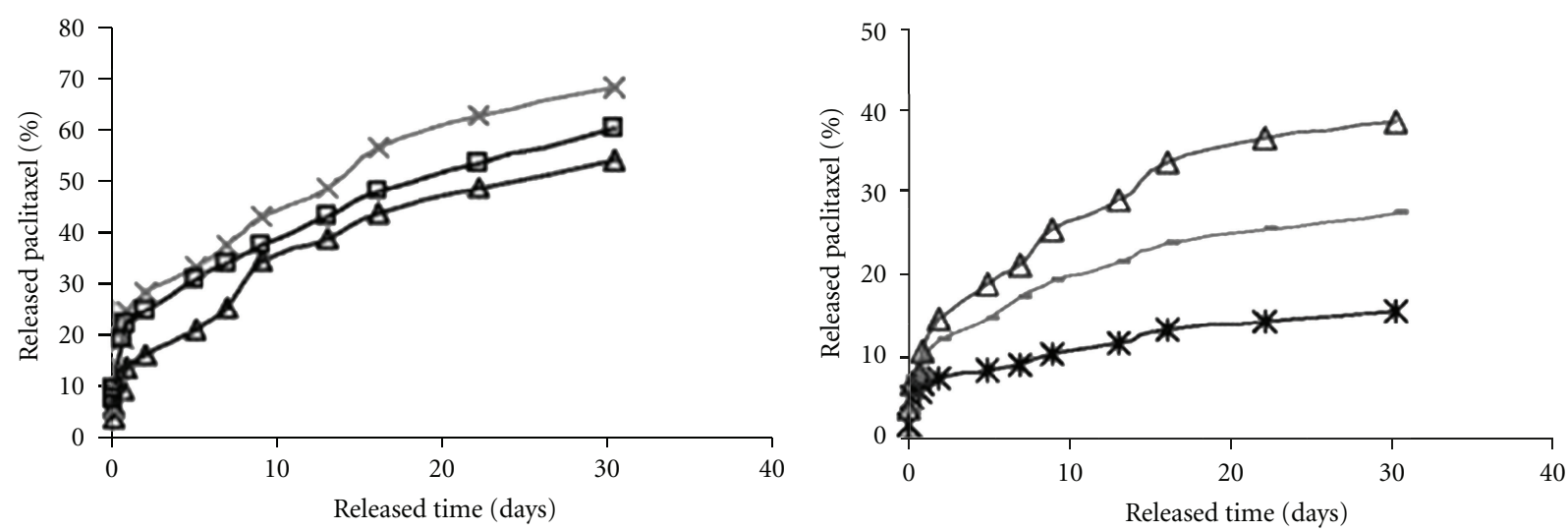

$\triangle$ E5
$\times \quad$ E7
$\square$ E8

(a)

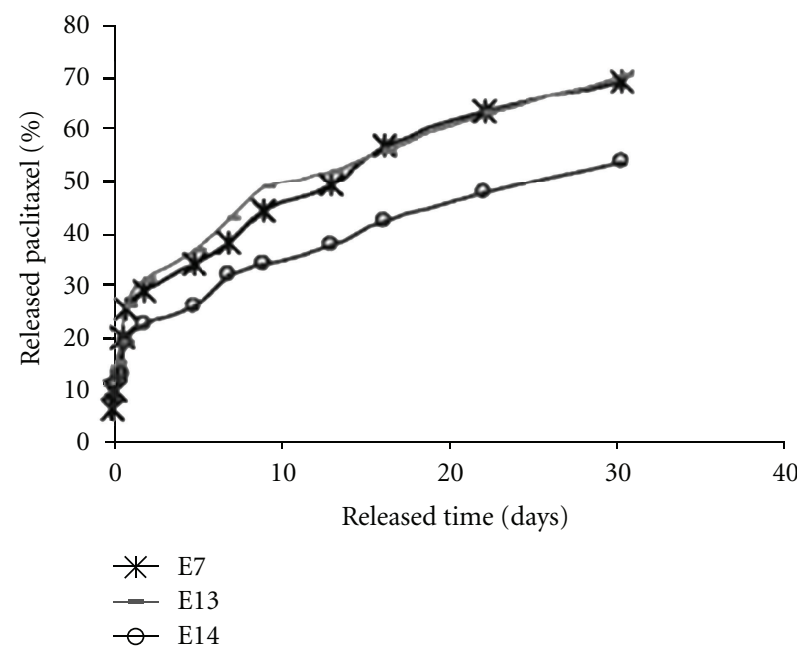

(c)

$$
\begin{aligned}
& \text { * M1 } \\
& -\triangle \mathrm{M} 2 \\
& \triangle \mathrm{M} 3
\end{aligned}
$$

(b)

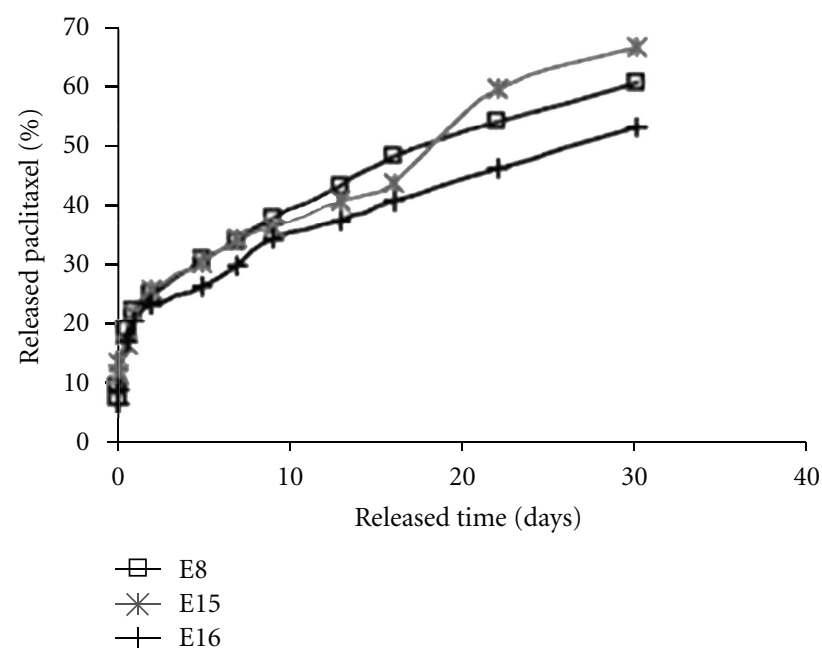

(d)

FIGURE 5: In vitro release curves of paclitaxel loaded nanoparticles prepared under various experiment parameters (a) E5 : PLA, E7 : PLGA (75:25), E8: PLGA (50:50); (b) ratio for PLGA-TPGS:M1 (2:1), M2 (1:1), M3 (1:2); (c) PLGA (75:25) concentration-E7:0.125, E13: 0.188, E14: 0.25; (d) PLGA (50:50) concentration-E8: 0.125, E15: 0.188, E16: 0.25 (reproduced with permission from Mu and Feng, [34]).

Ceruti et al. also compared conventional liposome formulations of paclitaxel with stealth-long circulating liposomes. The PEGylated liposomes were long circulating, with an elimination half-life of nearly $50 \mathrm{hrs}$ compared to less than $10 \mathrm{hrs}$ with conventional liposomes [52]. The group attempted to improve the solubilization and targeting of paclitaxel using water-soluble prodrugs, and incorporated $2^{\prime}$-succinyl-paclitaxel, $2^{\prime}$-methylpyridinium acetate paclitaxel and 2'-mPEG-paclitaxel in liposomes. The $2^{\prime}$-succinylpaclitaxel liposomes had superior stability at $4^{\circ} \mathrm{C}$ at both $\mathrm{pH}$ 5.8 or 7.4 for up to 6 days, but at $37^{\circ} \mathrm{C}$ the percentage of paclitaxel released increased from $4 \%$ to $12 \%$ (Figures $8(\mathrm{a}$ ) and $8(\mathrm{~b}))$ [52]. The half-life of this liposomal prodrug was longer than the free drug liposome formulations and the cytotoxic activity was similar to that of the free drug [52]. Sharma and Straubinger. prepared liposome formulations of paclitaxel using phospholipids in the molar ratio of $1: 33$ with phosphatidylcholine (PC) and phosphatidylglycerol (PG transestrified from egg PC) in the ratio 9:1. The liposomes were stable for more than 2 months at $4^{\circ} \mathrm{C}$ and 1 month at $20^{\circ} \mathrm{C}$. The stability of these liposomes as a function of \% PG and storage temperature is shown (Figure 9) [53]. The results are expressed as percentage of initial taxol concentration remaining in the liposomes at different time points. The formulations were well tolerated in mice when given via intravenous (IV) and intraperitoneal (IP) bolus doses. The maximum tolerated dose was found to be $>200 \mathrm{mg} / \mathrm{kg}$ for liposomal paclitaxel whereas it is only $30 \mathrm{mg} / \mathrm{kg}$ by IV and $50 \mathrm{mg} / \mathrm{kg}$ by IP route for free paclitaxel [53].

Sampedro et al. prepared liposomes using mixtures of phospholipids such as L-dimyristoyl phosphatidylcholine 


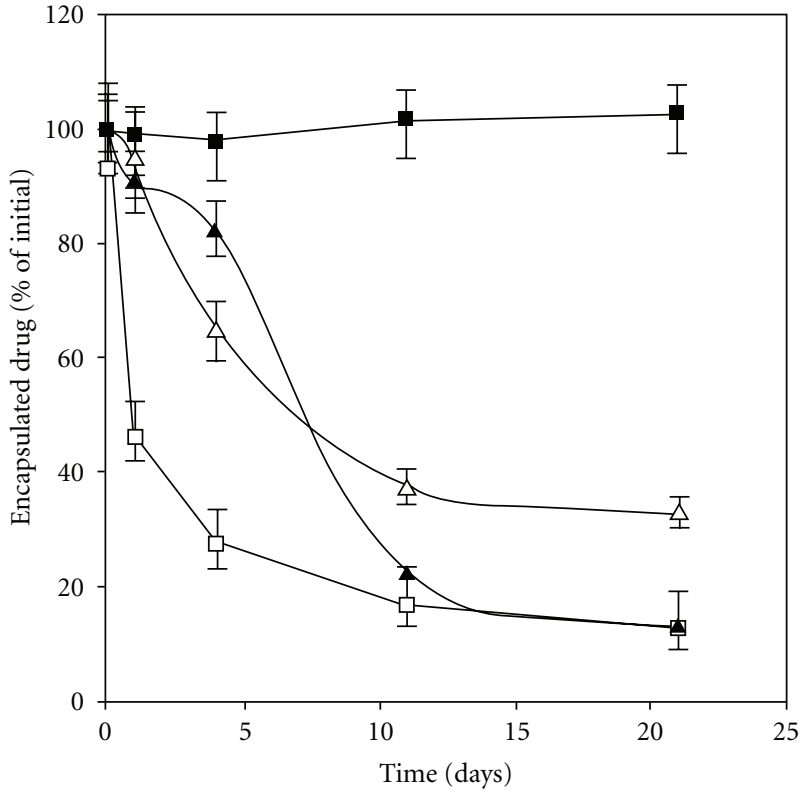

Figure 6: Release of paclitaxel from conventional (squares) and PEGylated (triangles) liposomes in storage conditions at $4^{\circ} \mathrm{C}$ (solid symbols), or in human plasma at $37^{\circ} \mathrm{C}$ (outline symbols) (reproduced with permission from Crosasso et al., [51]).

(DMPC) and L-dimyristoylphosphatidyl glycerol (DMPG), with or without cholesterol, by the standard evaporation/hydration method. Combination of the two phospholipids in the ratio of $7: 3$ and $9: 1$, with the addition of $5 \%$ cholesterol (w/w), conferred optimal results. The cytotoxicity of these liposome formulations in L1210 cells was found to be significantly greater than that of free paclitaxel [54]. Bartoli et al. compared the efficacy of paclitaxel in both nanoparticle and liposome formulations. They tested solutions of paclitaxel in DMSO and Cremophor EL against liposomal formulations, both in vitro and in vivo in P388 and L1210 leukemia models, and concluded that the liposome formulation of paclitaxel was superior both in vitro and in vivo, whereas the nanoparticle formulation was found to be toxic mainly because of its composition [55]. Straubinger et al. developed a series of liposome formulations, and the in vitro tests revealed that the liposomes retained growth-inhibitory activity while showing a delay of tumor progression against colon-26, a taxol-resistant murine tumor [56].

\section{Emulsion Systems}

An emulsion is a heterogenous system comprising of an aqueous phase dispersed in an oil phase, or vice versa, stabilized by an emulsifier. $\mathrm{O} / \mathrm{W}$ emulsion formulations for the delivery of anticancer drugs have generated interest, but are limited by the fact that many approved emulsifiers produce hemolytic reactions [57]. The drug should be incorporated completely into the dispersed phase to form a stable emulsion; therefore, the formulation of a drug as $\mathrm{O} / \mathrm{W}$ emulsion is possible only when the drug has adequate

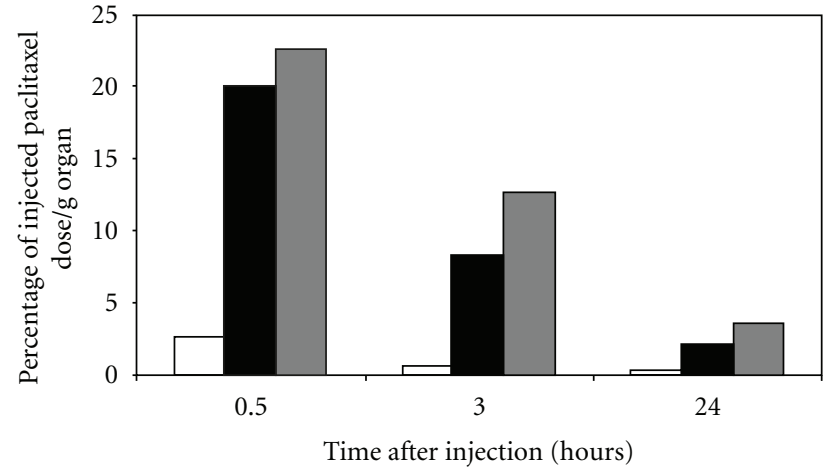

(a)

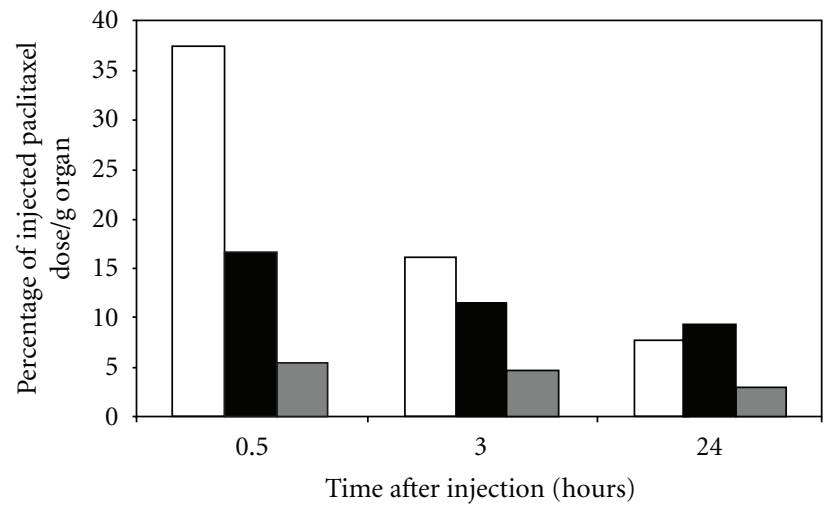

(b)

Figure 7: (a) Biodistribution in Balb/c mice in plasma (white), liver (black), and spleen (grey) $0.5,3$, and $24 \mathrm{hrs}$ after injection of conventional paclitaxel liposomes. Standard deviations were below $5 \%$ of the mean values (reproduced with permission from Crosasso et al., [51]). (b) Biodistribution in Balb/c mice in plasma (white), liver (black), and spleen (grey) $0.5,3$ and $24 \mathrm{hrs}$ after injection of PEGylated paclitaxel liposomes. Standard deviations were below 5\% of the mean values (reproduced with permission from Crosasso et al., [51]).

solubility in the oil phase [58]. Paclitaxel has limited solubility in soybean and similar vegetable oils; therefore, it prevents the use of simple $\mathrm{O} / \mathrm{W}$ emulsion for formulation [57].

Tarr and Yalkowsky prepared an $\mathrm{O} / \mathrm{W}$ emulsion of paclitaxel using triacetin as the internal phase. It was found that paclitaxel is highly soluble in triacetin $(75 \mathrm{mg} / \mathrm{mL})$. Regardless, the drug precipitates when the emulsion is diluted approximately nine times with $5 \%$ dextrose [59]. Tarr et al. prepared the first parenteral emulsion of paclitaxel containing $10-15 \mathrm{mg} / \mathrm{mL}$ paclitaxel in a vehicle composed of $50 \%$ triacetin, $1.5 \%$ soy-lecithin, $1.5 \%$ pluronic $\mathrm{F} 68$, and $2.0 \%$ ethyl oleate. About $10 \%$ of glycerol was added to prevent creaming [60]. Although this system was stable for a period of 6 months when stored at $4^{\circ} \mathrm{C}$, the amount of vehicle containing triacetin needed for delivering the therapeutic dose of paclitaxel was found to be toxic when administered intravenously to mice, and no antitumor activity was reported [60]. 


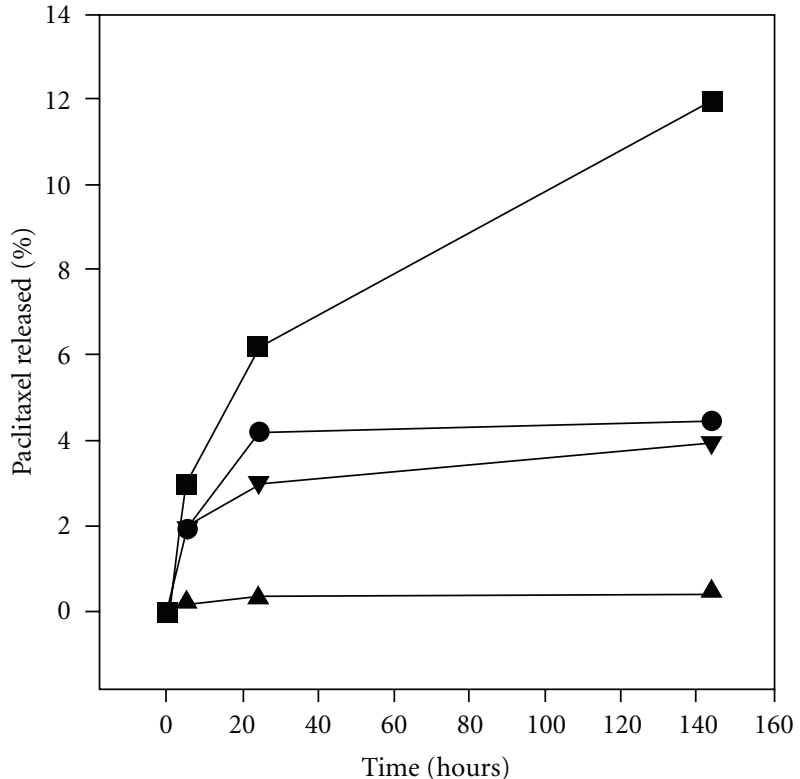

(a)

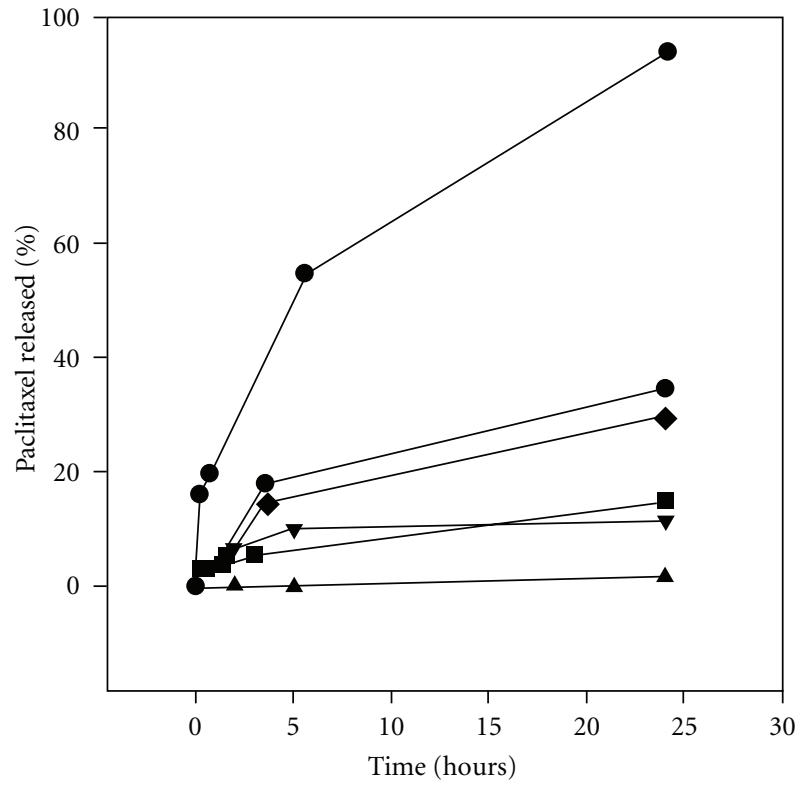

(b)

Figure 8: (a) Paclitaxel release at $4^{\circ} \mathrm{C}$ from $2^{\prime}$-PEG-paclitaxel (circles), $2^{\prime}$-succinyl-paclitaxel (triangles pointing up) and $2^{\prime}$-MPA-paclitaxel (triangles pointing down) in PBS buffer $\mathrm{pH}$ 5.8, 2' -PEG-paclitaxel (squares), 2' -succinyl-paclitaxel (triangles pointing up) and 2'-MPApaclitaxel (triangles pointing down) in PBS buffer $\mathrm{pH} 7.4$ (reproduced with permission from Ceruti et al., [52]). (b) Paclitaxel release at $37^{\circ} \mathrm{C}$ from $2^{\prime}$-PEG-paclitaxel (circles), $2^{\prime}$-succinyl-paclitaxel (triangles pointing down) and $2^{\prime}$-MPA-paclitaxel (hexagons) in PBS buffer $\mathrm{pH} 7.4,2^{\prime}$-PEG-paclitaxel (squares), $2^{\prime}$-succinyl-paclitaxel (triangles pointing up) and $2^{\prime}$-MPA-paclitaxel (diamonds) in PBS buffer pH 5.8 (reproduced with permission from Ceruti et al., [52]).

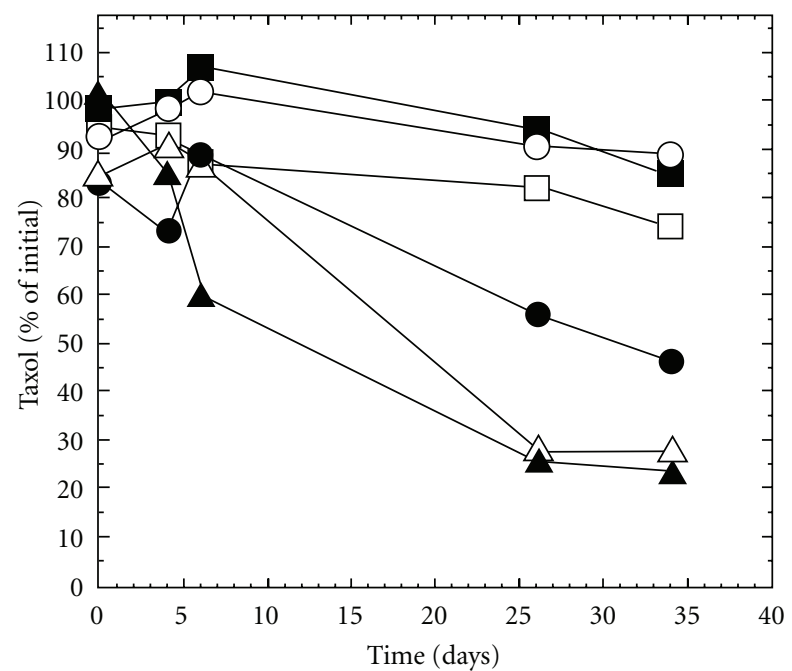

(a)

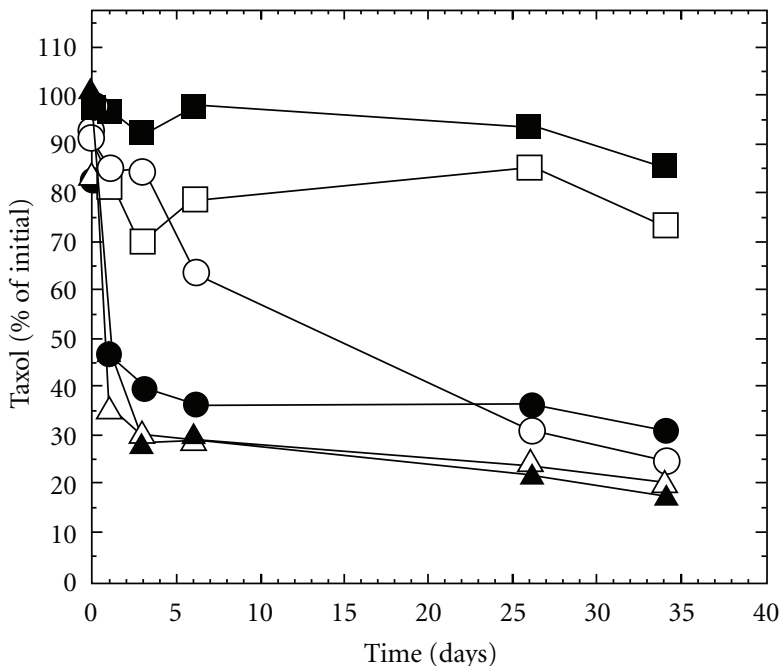

(b)

FIGURe 9: In these formulations the PG: PC ratio was varied. open squares: PC only; filled squares: PG: PC (1:9); open circles: PG: PC (3:7); filled circles: PG: PC (5:5); open triangles: PG:PC (7:3); filled triangles: PG only.(reproduced with permission from Sharma and Straubinger, [53]).

Kan et al. prepared O/W emulsions in which triacylglycerols were used to solubilize paclitaxel incorporated with various emulsifiers [61]. The antitumor activity was tested both in vitro and in vivo. The solubility of paclitaxel in oils such as tributylin, tricaproin, tricaprylin, soybean oil, corn oil, cottonseed oil, and mineral oil was determined
(Table 1) [61]. Paclitaxel had poor solubility in Tricaprylin (C8:0), with 8 carbons per hydrocarbon chain, compared to the short chain triacylglycerols such as tributyrin (C4:0) and tricaproin (C6:0). Triacetin (C2:0) resulted in a high solubility of paclitaxel $(75 \mathrm{mg} / \mathrm{mL})$ while mineral oil led to poor solubility because of its hydrocarbon structure. The 
TABLE 1: Solubility of paclitaxel in various oils (reproduced with permission from Kan et al. [61]).

\begin{tabular}{lc}
\hline Oil & Solubility of paclitaxel $(\mathrm{mg} / \mathrm{g})$ \\
\hline Tributyrin & 9.62 \\
Tricaproin & 9.03 \\
Tricaprylin & 1.19 \\
Corn oil & 0.23 \\
Soybean oil & 0.18 \\
Cotton seed oil & 0.14 \\
Mineral oil & Not detected \\
\hline
\end{tabular}

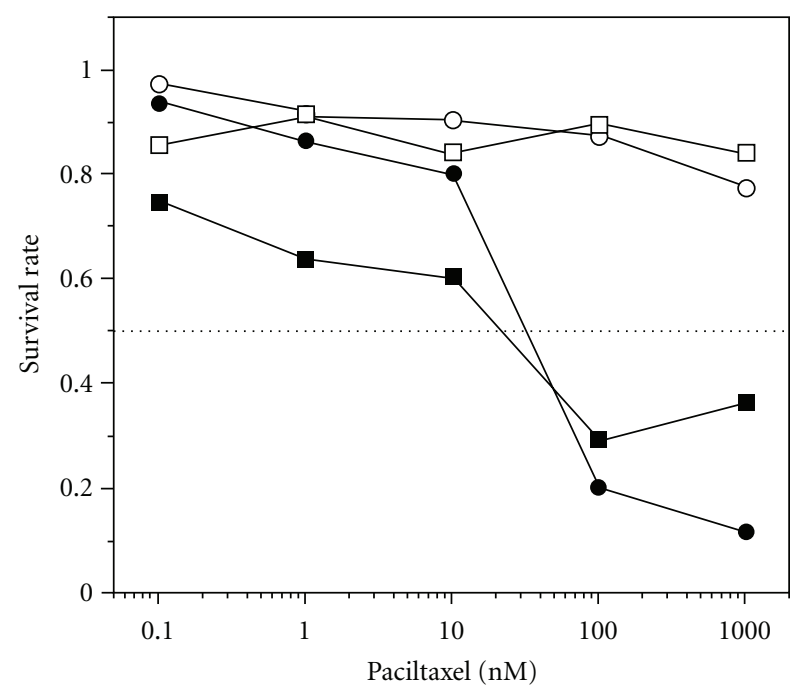

Figure 10: Survival rate of HeLa S-3 tumor cells exposing to emulsions and Diluent 12 with or without paclitaxel. • represents the formulated emulsion with paclitaxel, $\mathbf{\square}$ represents Diluent 12 containing $6 \mathrm{mg}$ paclitaxel in $1 \mathrm{~mL} \mathrm{50 \%} \mathrm{ethanol} \mathrm{and} \mathrm{50 \%} \mathrm{Cre-}$ mophor EL, respectively, $\bigcirc$ represents emulsion without paclitaxel, and $\square$ represents Diluent 12 without paclitaxel (reproduced with permission from Kan et al., [61]).

emulsions were prepared by dissolving egg phosphatidylcholine (EPC), Tween 80, and paclitaxel in the oil phase and mixing it with the aqueous phase containing $2.25 \% \mathrm{w} / \mathrm{v}$ of glycerol, followed by sonication and extrusion through a $0.22 \mu \mathrm{m}$ filter. The concentration of paclitaxel in emulsion for $50 \%$ inhibition $\left(\mathrm{IC}_{50}\right)$ of HeLa cells is approximately $30 \mathrm{nM}$, which is similar to paclitaxel in Diluent 12 (6 mg of paclitaxel in $1 \mathrm{~mL}$ of 50:50 ethanol: Cremophor EL). The survival of HeLa S-3 cells exposed to the test emulsions and Diluent 12, with or without paclitaxel, is shown in Figure 10 [61]. Ascitic-tumor-bearing mice were injected with the paclitaxel emulsion $(60 \mathrm{mg} / \mathrm{kg})$ and the vehicle; the vehicle did not increase the life span of the tumor bearing mice, but the emulsion increased the life span significantly (Figure 11) [61]. Even though the $\mathrm{IC}_{50}$ values are similar, the paclitaxel emulsion resulted in a longer lifespan than the Diluent 12paclitaxel formulation when given in equivalent doses of $30 \mathrm{mg} / \mathrm{kg}$ (Figure 12) [61].

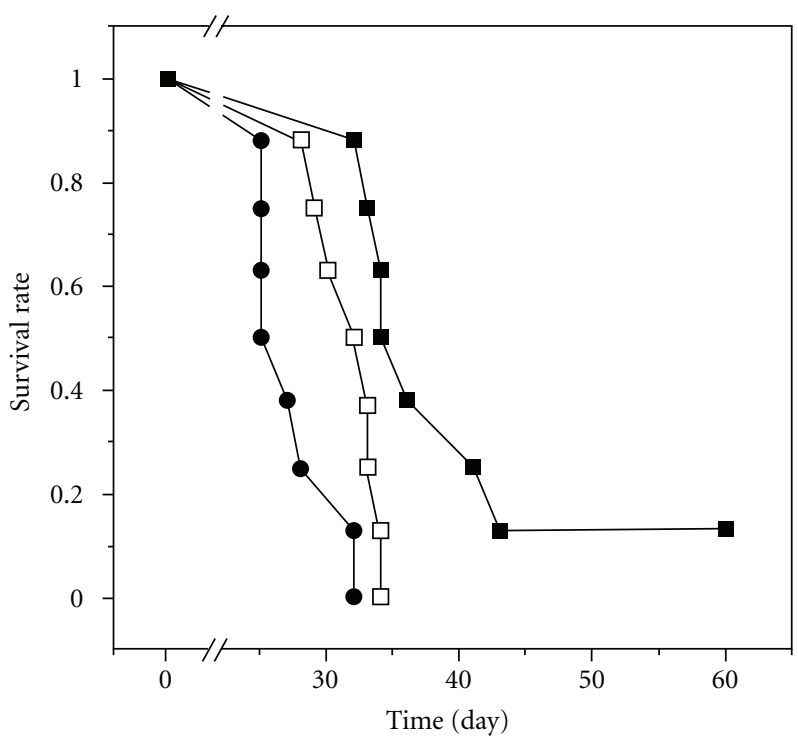

FIGURE 11: Survival ratio of ascitic tumor bearing mice. $\square$ represents untreated control, $\boldsymbol{\square}$ represents the group treated with $60 \mathrm{mg} / \mathrm{kg}$ paclitaxel emulsion, and - represents the group treated with same quantity of paclitaxel free emulsion vehicle (reproduced with permission from Kan et al., [61]).

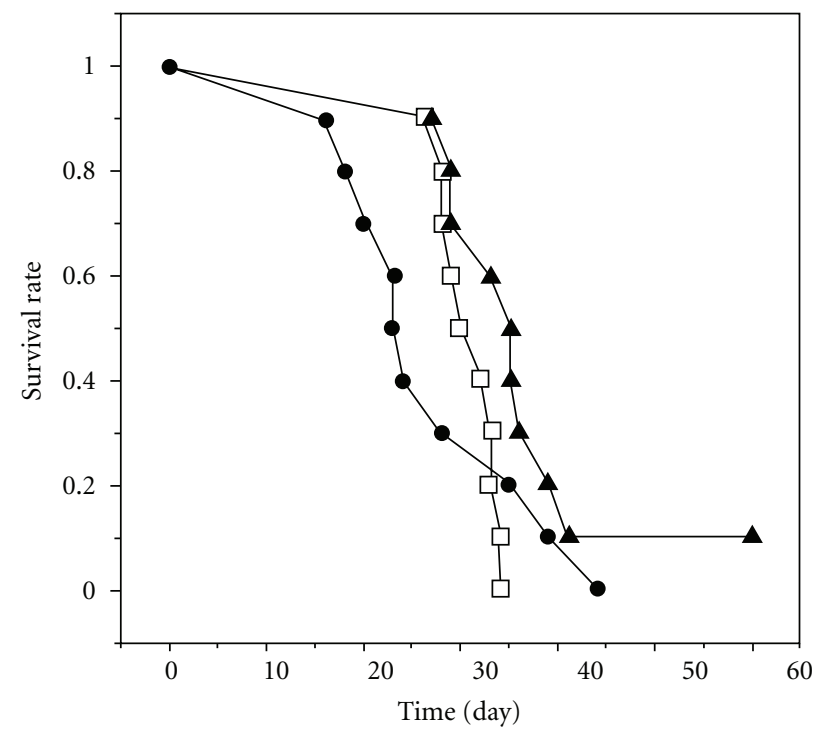

Figure 12: Comparison of treatment of Diluent 12 and emulsion on the ascitic tumor bearing mice. $\square$ represents untreated control, $\boldsymbol{\Delta}$ represents group treated with $30 \mathrm{mg} / \mathrm{kg}$ emulsion, and $\bullet$ represents group treated with Diluent 12 (reproduced with permission from Kan et al., [61]).

Constantinides et al. developed an injectable emulsion formulation containing paclitaxel $(8-10 \mathrm{mg} / \mathrm{mL})$ using Vitamin $\mathrm{E}$ as the oil phase [25]. The mean droplet diameter and $99 \%$ cumulative particle size distribution was less than $0.2 \mu \mathrm{m}$, therefore the emulsion could be filter sterilized. A preemulsion was prepared by adding $\alpha$-tocopherol in PEG 400 containing the surfactants TGPS and Pluronic F-127, with or without paclitaxel, to degassed water for injection. It 


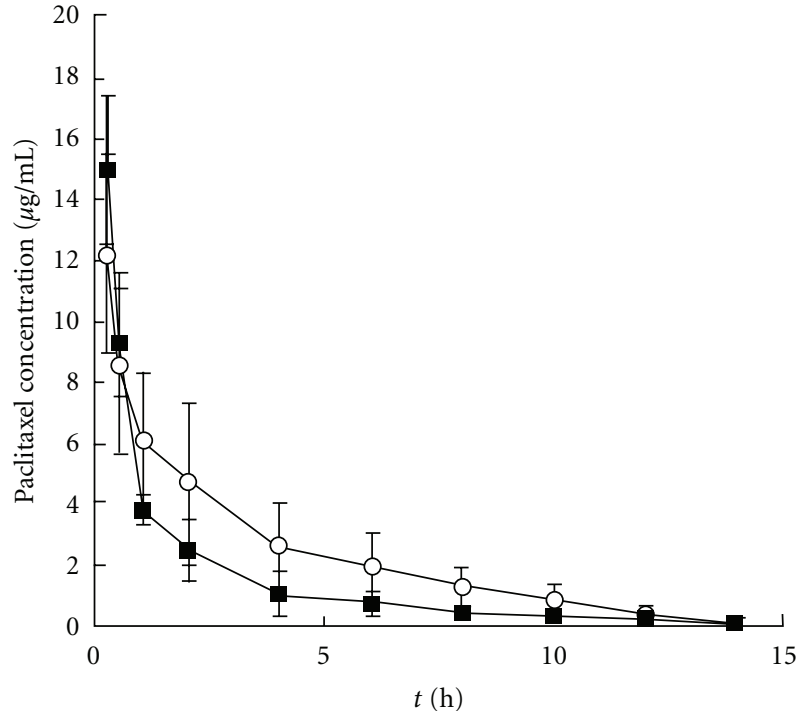

FIGURE 13: Mean plasma concentration of paclitaxel after IV administration of paclitaxel injection ( $\mathbf{\square})$ and paclitaxel microemulsion $(\bigcirc)$ in rats $(n=5)$ (reproduced with permission from $\mathrm{He}$ et al. [9]).

was mixed vigorously at $45^{\circ} \mathrm{C}$, followed by homogenization and sterile filtration through a $0.2 \mu \mathrm{m}$ Posidyne filter. Drug release from this emulsion was slower compared to Taxol, both in the presence or absence of human serum albumin. The tocopherol emulsion was better tolerated and more efficacious than Taxol in the melanoma tumor model mice [25].

He et al. prepared and evaluated a microemulsion formulation of paclitaxel with lower levels of solubilizers, anticipating less hypersensitivity reactions [9]. The hypersensitivity tests were done on guinea pigs. While the Taxol vehicle led to frequent nose-scratch, tremble, sneeze, erect hair, twitch, or dyspnea, with a grade of hypersensitivity equal to 3 , the microemulsion vehicle resulted in erect hair and less trembling, with a grade of 1 . The plasma concentration profile after a single dose of paclitaxel microemulsion injection is given in Figure 13 [9]. The data suggests that the microemulsion was able to increase the circulation time of paclitaxel in rats while maintaining a relatively higher plasma concentration [9].

Simamora et al. prepared two parenteral emulsions using benzyl benzoate and tributyrin as oil phase and Tween 80 and sorbitan monolaureate as emulsifiers with 5\% dextrose as the continuous phase. These formulations had minimal side effects, with no sign of phlebitis, in rabbits [62]. Lundberg prepared a lipid emulsion with triolein as oil phase and dipalmityl-phosphatidylcholine as the primary emulsifying agent [63]. Tween 80 and PEG-dipalmitoyl phosphatidylethanolamine were used as stabilizing agents. The emulsion resulted in prolonged circulation time for paclitaxel, while the in vitro cytotoxicity experiments indicated that its $\mathrm{IC}_{50}$ value was approximately $35 \mathrm{nM}$, which is comparable to Taxol. Lyophilization of this emulsion with $5 \%$ dextrose resulted in a stable product, which could

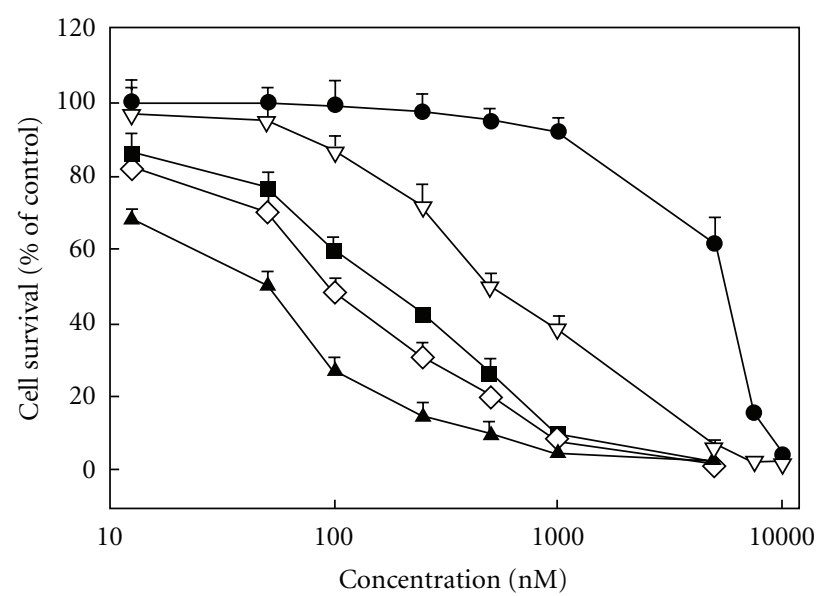

FIGURE 14: Inhibition of HeLa cell proliferation by paclitaxel oleate in lipid emulsions. Incubation times were $24(\bullet), 48(\nabla), 72(\bullet)$, and $96 \mathrm{~h}(\diamond)$. The effect of paclitaxel in Cremophor EL/ethanol at $48 \mathrm{~h}(\boldsymbol{\Delta})$ is shown as comparison. Control growth $=100$. Values are mean \pm S.D., $n=4$ (reproduced with permission from Lundberg et al., [64]).

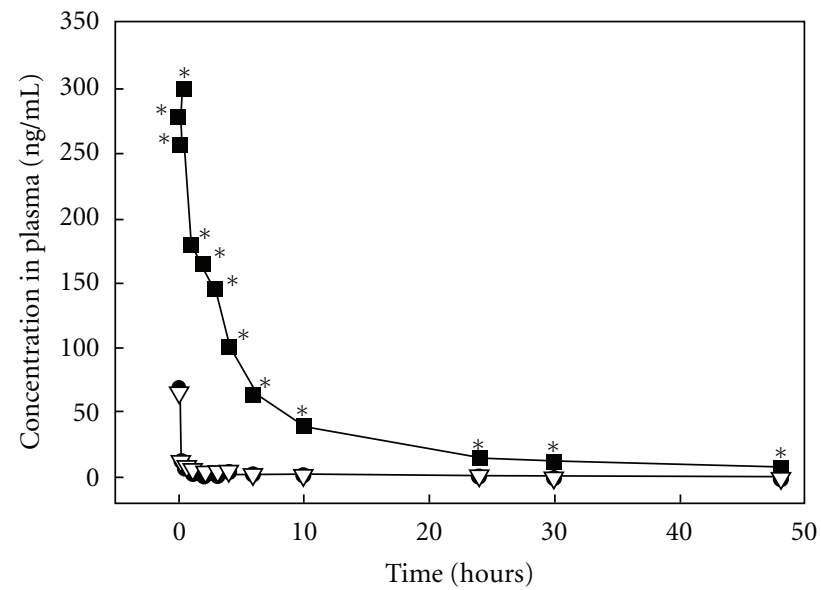

FIGURE 15: Drug concentration versus time curves of $\left[{ }^{3} \mathrm{H}\right]$ paclitaxel in lipid emulsion $(\bullet),\left[{ }^{3} \mathrm{H}\right]$ paclitaxel in Cremophor EL : ethanol $1: 1$ $(\mathrm{v} / \mathrm{v})(\nabla)$, and $\left[{ }^{3} \mathrm{H}\right]$ paclitaxel oleate in lipid emulsion $(\boldsymbol{\square})$ following single i.v. bolus. Values are mean \pm S.D., $n=3$. ${ }^{*} P<0.05$ versus paclitaxel in Cremophor EL/ethanol (reproduced with permission from Lundberg et al., [64]).

be successfully reconstituted with sterile water [63]. In subsequent research, the group incorporated a paclitaxel derivative, which consisted of a paclitaxel oleate in a nanosize lipid drug-carrier emulsion, and evaluated its pharmacokinetic profile [64]. The dose response curve in Figure 14 shows that paclitaxel oleate is cytotoxic, and the cytotoxic activity increases with an increase in incubation time [64]. The comparative pharmacokinetic profiles of paclitaxel lipid emulsion, Cremophor/ethanol formulation and paclitaxel in an oleate emulsion are shown in Figure 15 [64]. It was suggested that the plasma concentration of paclitaxel in the oleate emulsion was increased as a result of interaction with lipoproteins. 


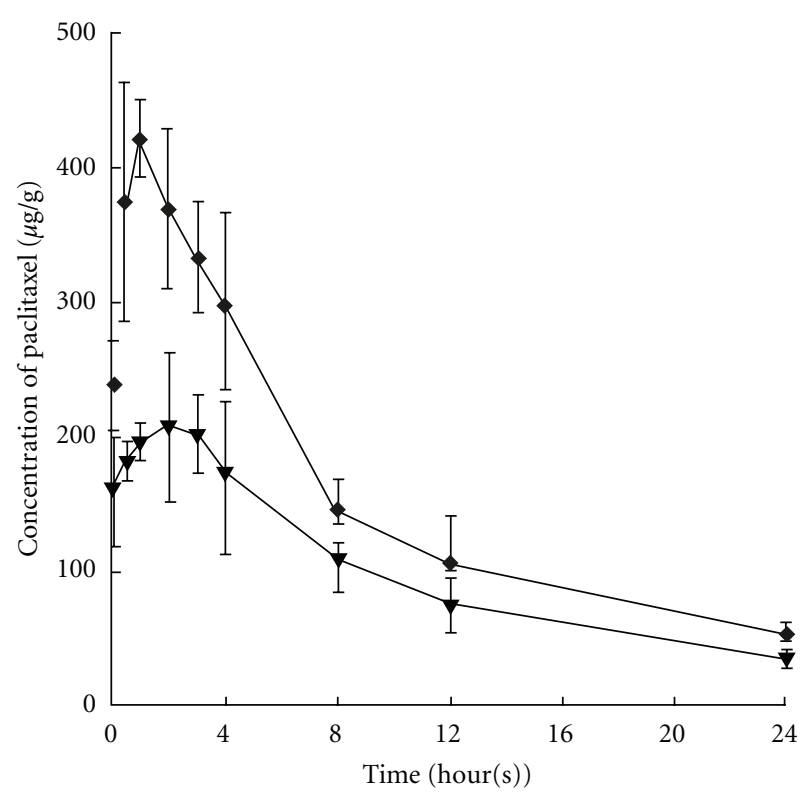

FIGURE 16: Time courses of paclitaxel levels in tumor of murine B16 melanoma-induced mice after i.v. administration of $50 \mathrm{mg} / \mathrm{kg}$ dose of Genexol-PM ( ) and $20 \mathrm{mg} / \mathrm{kg}$ dose of Taxol ( $\mathbf{\nabla})$. Each point represents the mean \pm S.D. of four mice per time point (reproduced with permission from Kim et al., [3]).

\section{Micelles}

The process of entrapping a hydrophobic drug in a biodegradable drug carrier micelle without covalent bonding to the micelle is called micellisation. A polymeric micelle consists of an aggregate of hydrophobic block copolymers with a diameter of $20-50 \mathrm{~nm}$, with a densely packed core, in which the hydrophobic drugs are incorporated by hydrophobic interactions. Among the block copolymers, the diblock copolymers are suitable for the formation of micelles because of their simple structure [3]. Micelles are convenient for use with anticancer drugs because they are structurally strong and avoid being captured by the MPS due to their particle size $[65,66]$.

Kim et al. prepared paclitaxel containing biodegradable polymeric micelles using a low molecular weight, nontoxic, biodegradable amphiphilic diblock copolymer called monomethoxy poly(ethylene glycol)-block-poly (D, L-lactide) (mPEG-PDLLA), and evaluated their pharmacokinetics. The polymeric micelles were prepared by the solid dispersion technique. The plasma concentration of paclitaxel in the polymeric micelles following IV administration in a murine B16 melanoma mice model is shown in Figure 16 [3]. The in vivo antitumor efficacy was evaluated in human ovarian tumor and human breast tumor xenografted nude mice. In the mice that received the polymeric micelles, a three-fold higher antitumor response was apparent compared to the Taxol formulation [3].

Zhang et al. also prepared micellar formulations of paclitaxel by incorporating paclitaxel in the diblock copolymer poly(d,l-lactide)-block-methoxy polyethylene glycol (PDLLA-MePEG). The survival time of the animals treated with paclitaxel micelles was increased and the lipoprotein distribution and plasma concentration were similar to that of Taxol. There was a five-fold increase in the maximum tolerated dose when the paclitaxel micelles were administered intraparenterally in P388 leukemia tumor bearing mice. The formulation's in vitro cytotoxicity was found to be similar to that of Taxol, and the dissolution studies confirmed that there was no precipitation of the drug following dilution [6769].

Miwa et al. used N-lauryl-carboxymethyl-chitosan (LCC) for the preparation of paclitaxel micelles of particle size less than $100 \mathrm{~nm}$. The concentration of paclitaxel was about $2.37 \mathrm{mg} / \mathrm{mL}$ in the micellar solution, which was reported to be more cytotoxic in vitro than free paclitaxel, particularly at low concentrations [70]. Alkan-Onyuksel et al. developed a mixed micellar formulation by solubilizing paclitaxel in a bile salt-phospholipid mixture using a coprecipitation method, which resulted in the formation of drug-loaded micelles [23]. The solubilization of paclitaxel was amplified with an increase in the molar ratio of bile salt/phospholipid and the total lipid concentration (Figures $17(\mathrm{a})$ and $17(\mathrm{~b}))$ [23]. Since the mixed micelles were not very stable when hydrated, they were freeze-dried to prolong storage stability. The mixed micellar formulation showed significant cytotoxicity and retained the antitumor activity. It was shown that the bile salt-phospholipid combination was 1.4 fold less toxic compared to Cremophor EL, therefore it could be concluded that the mixed micelles would be less toxic than Taxol for the same paclitaxel solubilization potential [23].

\section{Other Formulation Aspects}

8.1. Cosolvents. The solubility of hydrophobic drug molecules can be increased by the use of cosolvents such as glycerin, ethanol, propylene glycol, and N,N-dimethylacetamide. The use of these water miscible solvents is the most widely used technique to increase the solubility of drugs; indeed, the commercial formulation of paclitaxel is based upon cosolvents $[57,58]$. The stability of the compounds that are susceptible to hydrolysis can be increased by the elimination of water and use of these cosolvents [71]. The main disadvantage of cosolvent use is the risk of drug precipitation upon dilution in intravenous fluids or in the blood stream [72]. Tarr and Yalkowsky prepared a cosolvent system of paclitaxel $(5 \mathrm{mg} / \mathrm{ml})$ containing ethanol, tween 80 , and Pluronic L64 in the ratio of $3: 1: 6 \mathrm{v} / \mathrm{v} / \mathrm{v}$, as an alternative to Taxol. The solution was chemically and physically stable for 3 months, but dilution to a concentration of $3.45 \mathrm{mM}$ was found to be physically stable for only 3 days [73].

8.2. Cyclodextrins. Complexation with cyclodextrins (CyDs) is generally used to increase the solubility, dissolution rate, and bioavailability of poorly soluble drugs [74]. Lipophilic drugs are incorporated into the hydrophobic core of the cyclodextrins to form a noncovalent complex, such that the outer hydrophilic layer can freely interact with water. Adding a site-specific carrier to the complex could target the drug more specifically to tumors, thereby increasing the 


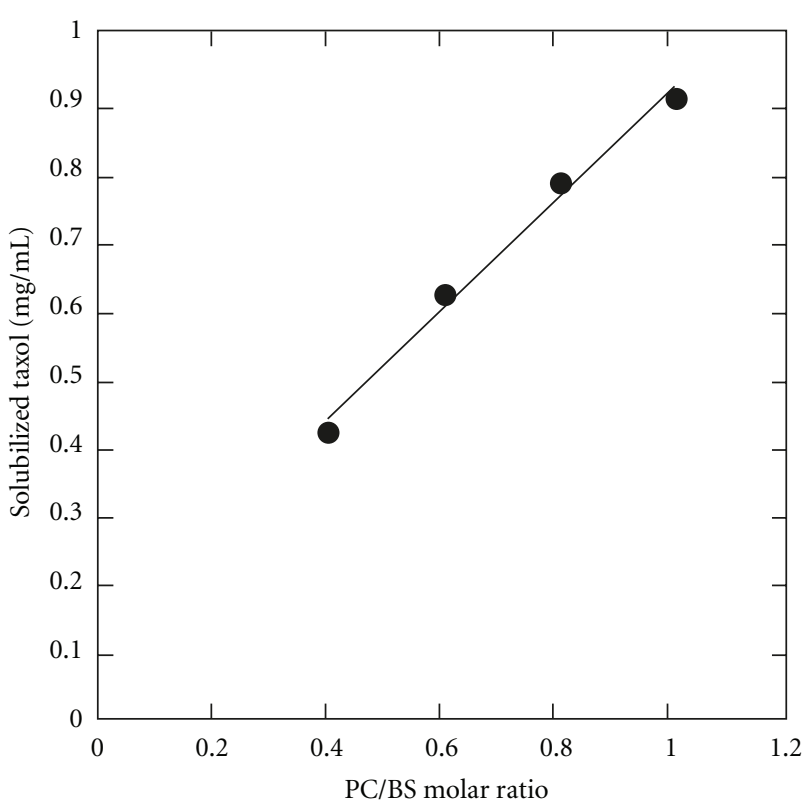

(a)

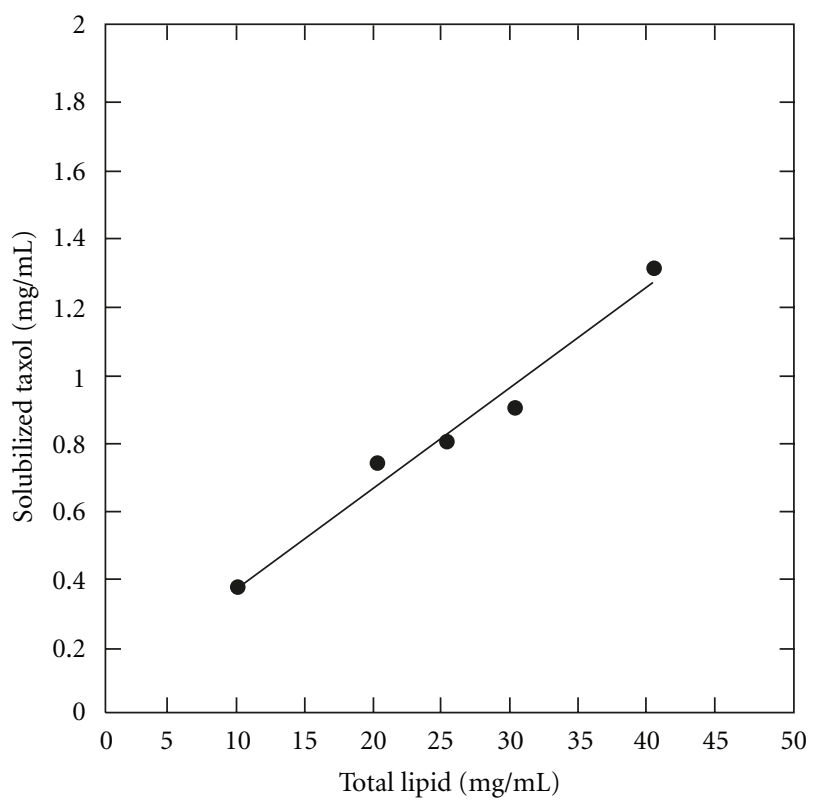

(b)

Figure 17: (a) Effect of PC/BS (phosphatidylcholine/bile salt) molar ratio on the solubilization potential of mixed micelles of taxol (reproduced with permission from Alkan-Onyuksel et al., [23]). (b) Effect of total lipid on the solubilization potential of mixed micelles of taxol (Reproduced with permission from Alkan-Onyuksel et al., [23])

therapeutic index. The main disadvantage of this kind of system is the risk of drug precipitation that might occur in situ upon dilution [57].

Sharma et al. experimented with $\beta$ and $\gamma$-CyD's because of their ability to solubilize paclitaxel, and their stability and efficacy [75]. $\beta$-CyD's increased the solubility of paclitaxel by 950-fold, easily achieving the clinically useful concentration of paclitaxel (1-4 mM); however, the CyD solutions were viscous and the removal of particulate matter became difficult. The chemically modified cyclodextrin, heptakis-2, 6-di-Omethyl- $\beta-\mathrm{CyD}$, solubilized paclitaxel to the greatest extent [75].

Cserhati et al. demonstrated the enhancement in solubility of paclitaxel by the use of hydroxyl propyl- $\beta$-CyD (HP $\beta$-CyD) [76]. It was postulated that due to the large taxane ring structure, the $\beta$ and $\gamma$-CyD's with large cavities would be more suitable than the small $\alpha$-CyD's for paclitaxel. The complexes formed with HP $\beta$-CyD were more stable than the complexes formed with HP $\gamma$-CyD or $\gamma$-CyD. However, it was observed that large amounts of CyD's were necessary to administer clinical doses of paclitaxel, which in turn causes significant renal toxicity and haemolysis [76].

8.3. Prodrugs. Prodrugs are therapeutically inactive derivatives of the parent drug and require biotransformation inside the body to convert to the active form of the drug. Depending on the design, prodrugs can increase the solubility of water insoluble compounds by several folds. However, the synthesis of prodrugs is expensive and complicated, and can greatly add to the expense of drug development, in addition to the possibility that the pharmacokinetic and pharmacodynamic properties of the parent drug can be altered $[57,58,71]$.

Mellado et al., during their development of acetylpaclitaxel, reported that the hydroxyl group at C-2 position is most preferred because it can be easily hydrolysed by enzymatic or chemical means [77]. Several paclitaxel C$2^{\prime}$ esters such as succinate-, glutarate-, and sulfonic acidimproved the water solubility and retained the in vivo activity. However, they were shown to experience chemical instability in aqueous solution [77].

Several C-2' and C-7' phosphate derivatives of paclitaxel were synthesized by Nuijen et al. and Vyas et al., which improved water solubility, but the in vitro release studies were disappointing, and their in vivo activity in M109 murine tumor bearing mice was insignificant [78, 79]. Ueda et al. synthesized derivatives of paclitaxel having a phosphonoxyphenyl-propionate ester group at the C-2' and $\mathrm{C}-7^{\prime}$ positions, which improved solubility and readily released paclitaxel, and the $\mathrm{C}-7^{\prime}$ derivative showed a comparable activity to paclitaxel in the M109 murine tumor model [80]. They also prepared 2' -oxycarbonylpaclitaxel-prodrugs, which were more stable against chemical and enzymatic hydrolysis and showed a very good in vitro release pattern with rapid accumulation of paclitaxel in HCT 116 human colon carcinoma cells [80]. Nicolaou et al. studied a group of derivatives called the "protaxols," which upon introduction of the functional group increase solubility and provide the ability for paclitaxel to initiate its own cleavage from the conjugate in situ [20]. The in vitro cytotoxicity of these protaxols was comparable to that of free paclitaxel, but their in vivo activity is yet to be established.

Greenwald et al. synthesized and evaluated $2^{\prime}$ and $7^{\prime}$ PEG paclitaxel esters, which were very soluble in water. The $2^{\prime}$ ester showed activity similar to paclitaxel, whereas the $7^{\prime}$ ester had reduced activity in vitro [21]. It was reported that the in vivo cytotoxicity significantly depended on the 
molecular weight of the solubilizing PEG-moiety. The group also investigated a 9 '-ester, which had paclitaxel linked to a $40 \mathrm{kD}$ PEG group and showed improved antitumor activity as well as an increased life expectancy for a group of mice with P388 murine leukemia tumors [22]. Similar prodrugs, conjugated with PEG (MW 5000) through a spacer-succinyl group tethered to the $2^{\prime}$ position of paclitaxel, prepared by Li et al., resulted in an improved solubility and comparable in vitro cytotoxicity to paclitaxel in B16 melanoma cells [81]. Pendriet al. demonstrated that PEG-conjugated paclitaxel2 '-glycinate had increased antitumor activity and less toxicity in a P388 murine leukemia model when compared to Taxol. This prodrug was also shown to have activity against HT-29, A549, and SKOV3 solid tumor bearing mice [82].

Dosio and coworkers developed a conjugate of paclitaxel with albumin since it is highly water-soluble and can preferentially accumulate in the tumor tissues because of its high vascular permeability and decreased lymphatic drainage [83]. N-hydroxy-3-sulfo-succinimide-paclitaxel was formed by esterification of paclitaxel with succinic anhydride at the $2^{\prime}$-position and subsequent derivatization, which was linked to the lysyl amino groups of the human serum albumin (HAS). Although in vivo studies showed that paclitaxel is released slowly and continuously over prolonged periods of time, in vitro studies showed that free paclitaxel was 410 times more active than the conjugated paclitaxel [83]. Presenti et al. synthesized a highly water-soluble polymer, hydroxy propyl methacrylamide (HPMA), linked at the $2^{\prime}$ position of paclitaxel through a four-aminoacid chain (GlyPhe-leu-Gly) [84]. The prodrug is cleavable by esterases at the amino acid spacer thus releasing free paclitaxel in the blood stream. This compound showed improved antitumor activity and less toxicity when tested against the M109 murine lung cancer cells and also M5076 murine reticulosarcoma [84].

8.4. Stents. Stents are devices used to prevent coronary restenosis by limiting the extent of elastic recoiling and late vascular remodeling following stent angioplasty $[85,86]$. Paclitaxel was shown to inhibit the vascular smooth muscle cell migration and proliferation contributing to neointimal hyperplasia, and the concept led to the commercial development of the paclitaxel coated Taxus stent. After an initial failure with polymer-coated stents, which caused intense inflammation, severe luminal narrowing, thrombosis, and death, Heldman et al. prepared paclitaxel coated coronary stents by the dip-coating method where paclitaxel is dissolved in a volatile solvent [85]. This method was suitable because the complications associated with the polymers were avoided and it allowed for immediate contact of paclitaxel with the vessel wall and rapid accumulation in the arterial tissue. Paclitaxel coated Palmaz-Schatz stents were placed in the left anterior descending artery of 43 pigs, where all the pigs survived without any evidence of myocardial infarction. After 4 weeks, the angiograms of the highest dose of paclitaxel revealed the largest reduction in neointimal infringement. In the control group, it was clear that there was a distinctive narrowing of the stented artery, therefore the inhibition of tissue hyperplasia with the paclitaxel-coated stents was highly significant [85]. Boston Scientific Corporation uses a biodegradable polymer to coat paclitaxel on their Taxus stents.

8.5. Local Drug Delivery. The preferred and successful treatment for solid tumors remains surgery, followed by irradiation to kill the malignant cells that survived surgery. This treatment regimen is frequently followed by chemotherapy, which has devastating consequences on the patient's quality of life because of the toxic side effects of the anticancer drugs. In this scenario, the postsurgical local placement of a biodegradable device loaded with an anticancer agent can prevent further proliferation of malignant cells while sparing the patient the harmful side effects of chemotherapy.

Park et al. developed disc-shaped implants of polyanhydride P (FAD-SA $50: 50 \mathrm{w} / \mathrm{w}$ ) with $10 \% \mathrm{w} / \mathrm{w}$ paclitaxel, from which the drug was slowly released with only $15 \%$ of the drug released in 77 days, and requiring 44 months to release the total amount of paclitaxel [87]. Similar formulations were used for localized implantation of drug in the cavity of resected brain tumors [88]. Winternitz et al. developed a polymeric surgical paste by blending $1-30 \% \mathrm{w} / \mathrm{w}$ of paclitaxel in PCL and MePEG (MW 350) [89]. The in vitro drug release studies revealed that $10-15 \%$ of paclitaxel was released over a 3-week period, and the $20 \% \mathrm{w} / \mathrm{w}$ paclitaxel paste showed complete inhibition of tumor regrowth when implanted in MDAY D2 solid tumor bearing mice [89].

\section{Conclusion}

Paclitaxel is effective against a wide range of cancers that are obstinate to conventional therapy. Developing a suitable carrier system for this drug has proved to be a challenge due to the physicochemical characteristics of the drug, and although widely used, the commercially available solution dosage form of paclitaxel remains far from ideal due to toxicities resulting from the vehicle. Nanoparticles and liposomes are suggested as potentially better options for delivery of this drug as they can minimize detrimental toxicities while enhancing the therapeutic efficacy of paclitaxel. The premise of this paper was to discuss the different formulation options of paclitaxel, including nanoparticles and liposomes, which have the potential to overcome previously encountered limitations in therapy.

\section{Disclosure}

The authors have no relevant affiliations or financial involvement with any organization or entity with a financial interest in or financial conflict with the subject matter or materials discussed in the paper. This includes employment, consultancies, honoraria, stock ownership or options, expert testimony, grants or patents received or pending, or royalties. No writing assistance was utilized in the production of this paper. 


\section{Acknowledgment}

Authors wish to thank Dr. Vijay Sutariya for his help in compiling figures.

\section{References}

[1] D. Mastropaolo, A. Camerman, Y. Luo, G. D. Brayer, and N. Camerman, "Crystal and molecular structure of paclitaxel (taxol)," Proceedings of the National Academy of Sciences of the United States of America, vol. 92, no. 15, pp. 6920-6924, 1995.

[2] V. Farina, The Chemistry and Pharmacology of Taxol and Its Derivatives, Elsevier Science, 1995.

[3] S. C. Kim, D. W. Kim, Y. H. Shim et al., "In vivo evaluation of polymeric micellar paclitaxel formulation: toxicity and efficacy," Journal of Controlled Release, vol. 72, no. 1-3, pp. 191-202, 2001.

[4] A. K. Singla, A. Garg, and D. Aggarwal, "Paclitaxel and its formulations," International Journal of Pharmaceutics, vol. 235, no. 1-2, pp. 179-192, 2002.

[5] W. P. McGuire, E. K. Rowinsky, N. B. Rosenhein et al., "Taxol: a unique antineoplastic agent with significant activity in advanced ovarian epithelial neoplasms," Annals of Internal Medicine, vol. 111, no. 4, pp. 273-279, 1989.

[6] F. A. Holmes, R. S. Walters, R. L. Theriault et al., "Phase II trial of taxol, an active drug in the treatment of metastatic breast cancer," Journal of the National Cancer Institute, vol. 83, no. 24, pp. 1797-1805, 1991.

[7] C. Dumontet and B. I. Sikic, "Mechanisms of action of and resistance to antitubulin agents: microtubule dynamics, drug transport, and cell death," Journal of Clinical Oncology, vol. 17, no. 3, pp. 1061-1070, 1999.

[8] M. E. Stearns and M. Wang, "Taxol blocks processes essential for prostate tumor cell (PC-3 ML) invasion and metastases," Cancer Research, vol. 52, no. 13, pp. 3776-3781, 1992.

[9] L. He, G. L. Wang, and Q. Zhang, "An alternative paclitaxel microemulsion formulation: hypersensitivity evaluation and pharmacokinetic profile," International Journal of Pharmaceutics, vol. 250, no. 1, pp. 45-50, 2003.

[10] K. C. Nicolaou, Z. Yang, J. J. Liu et al., "Total synthesis of taxol," Nature, vol. 367, no. 6464, pp. 630-634, 1994.

[11] R. A. Holton, C. Somoza, H. B. Kim et al., "First total synthesis of taxol," Journal of the American Chemical Society, vol. 116, no. 4, pp. 1597-1598, 1994.

[12] P. A. Wander, M. G. Natchus, and A. J. Shuker, "Towards the total synthesis of taxol and its analogues," in Taxol: Science and applications, M. Suffness, Ed., pp. 123-190, CRC Press, New York, NY, USA, 1995.

[13] R. M. Straubinger, "Biopharmaceutics of paclitaxel (Taxol): formulation, activity and pharmacokinetics," in Taxol: Science and Applications, M. Suffness, Ed., pp. 237-258, CRC Press, 1996.

[14] P. Couvreur, P. Tulkens, M. Roland, A. Trouet, and P. Speiser, "Nanocapsules: a new type of lysosomotropic carrier," FEBS Letters, vol. 84, no. 2, pp. 323-326, 1977.

[15] P. Couvreur, B. Kante, V. Lenaerts, V. Scailteur, M. Roland, and P. Speiser, "Tissue distribution of antitumor drugs associated with polyalkylcyanoacrylate nanoparticles," Journal of Pharmaceutical Sciences, vol. 69, no. 2, pp. 199-202, 1980.

[16] J. D. Adams, K. P. Flora, B. R. Goldspiel, J. W. Wilson, and R. Finley, "Taxol: a history of pharmaceutical development and current pharmaceutical concerns," Journal of the National Cancer Institute. Monographs, no. 15, pp. 141-147, 1993.
[17] P. Couvreur, P. Tulkens, M. Roland, A. Trouet, and P. Speiser, "Nanocapsules: a new type of lysosomotropic carrier," FEBS Letters, vol. 84, no. 2, pp. 323-326, 1977.

[18] W. Mellado, N. F. Magri, D. G. I. Kingston, R. Garcia-Arenas, G. A. Orr, and S. B. horwitz, "Preparation and biological activity of taxol acetates," Biochemical and Biophysical Research Communications, vol. 124, no. 2, pp. 329-336, 1984.

[19] H. M. Deutsch, J. A. Glinski, M. Hernandez et al., "Synthesis of congeners and prodrugs. 3. Water-soluble prodrugs of taxol with potent antitumor activity," Journal of Medicinal Chemistry, vol. 32, no. 4, pp. 788-792, 1989.

[20] K. C. Nicolaou, C. Riemer, M. A. Kerr, D. Rideout, and W. Wrasidio, "Design, synthesis and biological activity of protaxols," Nature, vol. 364, no. 6436, pp. 464-466, 1993.

[21] R. B. Greenwald, A. Pendri, D. Bolikal, and C. W. Gilbert, "Highly water soluble taxol derivatives: 2'-Polyethyleneglycol esters as potential prodrugs," Bioorganic and Medicinal Chemistry Letters, vol. 4, no. 20, pp. 2465-2470, 1994.

[22] R. B. Greenwald, C. W. Gilbert, A. Pendri, C. D. Conover, J. Xia, and A. Martinez, "Water soluble taxol: 2'-poly(ethylene glycol) ester prodrugs-design and in vivo effectiveness," Journal of Medicinal Chemistry, vol. 39, no. 2, pp. 424-431, 1996.

[23] H. Alkan-Onyuksel, S. Ramakrishnan, H. B. Chai, and J. M. Pezzuto, "A mixed micellar formulation suitable for the parenteral administration of taxol," Pharmaceutical Research, vol. 11, no. 2, pp. 206-212, 1994.

[24] E. Merisko-Liversidge, P. Sarpotdar, J. Bruno et al., "Formulation and antitumor activity evaluation of nanocrystalline suspensions of poorly soluble anticancer drugs," Pharmaceutical Research, vol. 13, no. 2, pp. 272-278, 1996.

[25] P. P. Constantinides, K. J. Lambert, A. K. Tustian et al., "Formulation development and antitumor activity of a filtersterilizable emulsion of paclitaxel," Pharmaceutical Research, vol. 17, no. 2, pp. 175-182, 2000.

[26] R. B. Weiss, R. C. Donehower, P. H. Wiernik et al., "Hypersensitivity reactions from taxol," Journal of Clinical Oncology, vol. 8, no. 7, pp. 1263-1268, 1990.

[27] E. K. Rowinsky, E. A. Eisenhauer, V. Chaudhry, S. G. Arbuck, and R. C. Donehower, "Clinical toxicities encountered with paclitaxel (Taxol)," Seminars in Oncology, vol. 20, no. 4, pp. $1-15,1993$.

[28] W. Lorenz, H. J. Reimann, A. Schmal et al., "Histamine release in dogs by cremophor E1 and its derivatives: oxethylated oleic acid is the most effective constituent," Agents and Actions, vol. 7, no. 1, pp. 63-67, 1977.

[29] D. Dye and J. Watkins, "Suspected anaphylactic reaction to Cremophor EL," BMJ, vol. 280, no. 6228, article 1353, 1980.

[30] K. Paál, J. Müller, and L. Hegedûs, "High affinity binding of paclitaxel to human serum albumin," European Journal of Biochemistry, vol. 268, no. 7, pp. 2187-2191, 2001.

[31] N. Desai, V. Trieu, Z. Yao et al., "Increased antitumor activity, intratumor paclitaxel concentrations, and endothelial cell transport of cremophor-free, albumin-bound paclitaxel, ABI007, compared with cremophor-based paclitaxel," Clinical Cancer Research, vol. 12, no. 4, pp. 1317-1324, 2006.

[32] N. K. Ibrahim, N. Desai, S. Legha et al., "Phase I and pharmacokinetic study of ABI-007, a cremophor-free, proteinstabilized, nanoparticle formulation of paclitaxel," Clinical Cancer Research, vol. 8, no. 5, pp. 1038-1044, 2002.

[33] C. Fonseca, S. Simões, and R. Gaspar, "Paclitaxel-loaded PLGA nanoparticles: preparation, physicochemical characterization and in vitro anti-tumoral activity," Journal of Controlled Release, vol. 83, no. 2, pp. 273-286, 2002. 
[34] L. Mu and S. S. Feng, "A novel controlled release formulation for the anticancer drug paclitaxel (Taxol): PLGA nanoparticles containing vitamin E TPGS," Journal of Controlled Release, vol. 86, no. 1, pp. 33-48, 2003.

[35] L. Brannon-Peppas, "Recent advances on the use of biodegradable microparticles and nanoparticles in controlled drug delivery," International Journal of Pharmaceutics, vol. 116, no. 1, pp. 1-9, 1995.

[36] P. Maincent, R. Le Verge, and P. Sado, "Disposition kinetics and oral bioavailability of vincamine-loaded polyalkyl cyanoacrylate nanoparticles," Journal of Pharmaceutical Sciences, vol. 75, no. 10, pp. 955-958, 1986.

[37] A. Rolland, "Clinical pharmacokinetics of doxorubicin in hepatoma patients after a single intravenous injection of free or nanoparticle-bound anthracycline," International Journal of Pharmaceutics, vol. 54, no. 2, pp. 113-121, 1989.

[38] D. Sharma, T. P. Chelvi, J. Kaur et al., "Novel Taxol formulation: polyvinylpyrrolidone nanoparticle- encapsulated Taxol for drug delivery in cancer therapy," Oncology Research, vol. 8, no. 7-8, pp. 281-286, 1996.

[39] J. C. Leroux, E. Doelker, and R. Gurny, "The use of drug loaded nanoparticles in cancer chemotherapy," in Microencapsulation: Methods and Industrial Applications, S. Benita, Ed., pp. 535575, Marcel Dekker, New York, NY, USA, 1996.

[40] W. L. Monsky, D. Fukumura, T. Gohongi et al., "Augmentation of transvascular transport of macromolecules and nanoparticles in tumors using vascular endothelial growth factor," Cancer Research, vol. 59, no. 16, pp. 4129-4135, 1999.

[41] P. Beck, J. Kreuter, R. Reszka, and I. Fichtner, "Influence of polybutylcyanoacrylate nanoparticles and liposomes on the efficacy and toxicity of the anticancer drug mitoxantrone in murine tumour models," Journal of Microencapsulation, vol. 10, no. 1, pp. 101-114, 1993.

[42] M. Simeonova, M. Ilarionova, T. Ivanova, C. Konstantinov, and D. Todorov, "Nanoparticles as drugs carriers for vinblastine. acute toxicity of vinblastine in a free form and associated to polybutylcyanoacrylate nanoparticles," Acta Physiologica et Pharmacologica Bulgarica, vol. 17, no. 4, pp. 43-49, 1991.

[43] A. Oliver, "Taxol: finite supply and increasing demand," Montana Pharmacist, vol. 17, pp. 17-18, 1993.

[44] S. Bennis, C. Chapey, P. Couvreur, and J. Robert, "Enhanced cytotoxicity of doxorubicin encapsulated in polyisohexylcyanoacrylate nanospheres against multidrug-resistant tumour cells in culture," European Journal of Cancer A, vol. 30, no. 1, pp. 89-93, 1994.

[45] E. K. Rowinsky and R. C. Donehower, "Drug therapy: paclitaxel," The New England Journal of Medicine, vol. 332, no. 15, pp. 1004-1014, 1995.

[46] B. Magenheim and S. Benita, "Nanoparticle characterization: a comprehensive physicochemical approach," Socialism, vol. 1, no. 4, pp. 221-241, 1991.

[47] F. Si-Shen and H. Guofeng, "Effects of emulsifiers on the controlled release of paclitaxel (Taxol) from nanospheres of biodegradable polymers," Journal of Controlled Release, vol. 71, no. 1, pp. 53-69, 2001.

[48] R. H. Müller and K. Peters, "Nanosuspensions for the formulation of poorly soluble drugs. I. preparation by a size-reduction technique," International Journal of Pharmaceutics, vol. 160, no. 2, pp. 229-237, 1998.

[49] P. Soon-Shiong, N. P. Desai, M. W. Grinstaff, P. Sandford, A. Suslick, and S. Kenneth, "Method for in vivo delivery of substantially water insoluble pharmacologically active agents and composition," USA Patent 5, 560, 933, October 1996.
[50] A. Sharma, E. Mayhew, and R. M. Straubinger, "Antitumor effect of taxol-containing liposomes in a taxol-resistant murine tumor model," Cancer Research, vol. 53, no. 24, pp. 5877-5881, 1993.

[51] P. Crosasso, M. Ceruti, P. Brusa, S. Arpicco, F. Dosio, and L. Cattel, "Preparation, characterization and properties of sterically stabilized paclitaxel-containing liposomes," Journal of Controlled Release, vol. 63, no. 1-2, pp. 19-30, 2000.

[52] M. Ceruti, P. Crosasso, P. Brusa, S. Arpicco, F. Dosio, and L. Cattel, "Preparation, characterization, cytotoxicity and pharmacokinetics of liposomes containing water-soluble prodrugs of paclitaxel," Journal of Controlled Release, vol. 63, no. 1-2, pp. 141-153, 2000.

[53] A. Sharma and R. M. Straubinger, "Novel taxol formulations: preparation and characterization of taxol-containing liposomes," Pharmaceutical Research, vol. 11, no. 6, pp. 889896, 1994.

[54] F. Sampedro, J. Partika, P. Santalo, A. M. Molins-Pujol, J. Bonal, and R. Perez-Soler, "Liposomes as carriers of different new lipophilic antitumour drugs: a preliminary report," Journal of Microencapsulation, vol. 11, no. 3, pp. 309-318, 1994.

[55] M. H. Bartoli, M. Boitard, H. Fessi et al., "In vitro and in vivo antitumoral activity of free, and encapsulated taxol," Journal of Microencapsulation, vol. 7, no. 2, pp. 191-197, 1990.

[56] R. M. Straubinger, A. Sharma, M. Murray, and E. Mayhew, "Novel Taxol formulations: taxol-containing liposomes," Journal of the National Cancer Institute. Monographs, no. 15, pp. 69-78, 1993.

[57] J. M. Meerum Terwogt, B. Nuijen, W. W. Ten Bokkel Huinink, and J. H. Beijnen, "Alternative formulations of paclitaxel," Cancer Treatment Reviews, vol. 23, no. 2, pp. 87-95, 1997.

[58] B. Nuijen, M. Bouma, J. H. M. Schellens, and J. H. Beijnen, "Progress in the development of alternative pharmaceutical formulations of taxanes," Investigational New Drugs, vol. 19, no. 2, pp. 143-153, 2001.

[59] B. D. Tarr and S. H. Yalkowsky, "A new parenteral vehicle for the adminstration of some poorly water soluble anti-cancer drugs," Journal of Parenteral Science and Technology, vol. 41, no. 1, pp. 31-33, 1987.

[60] B. D. Tarr, T. G. Sambandan, and S. H. Yalkowsky, "A new parental emulsion for the administration of taxol," Pharmaceutical Research, vol. 4, no. 2, pp. 162-165, 1987.

[61] P. Kan, Z. B. Chen, C. J. Lee, and I. M. Chu, "Development of nonionic surfactant/phospholipid o/w emulsion as a paclitaxel delivery system," Journal of Controlled Release, vol. 58, no. 3, pp. 271-278, 1999.

[62] P. Simamora, R. M. Dannenfelser, S. E. Tabibi, and S. H. Yalkowsky, "Emulsion formulations for intravenous administration of paclitaxel," PDA Journal of Pharmaceutical Science and Technology, vol. 52, no. 4, pp. 170-172, 1998.

[63] B. B. Lundberg, "A submicron lipid emulsion coated with amphipathic polyethylene glycol for parenteral administration of paclitaxel (Taxol)," Journal of Pharmacy and Pharmacology, vol. 49, no. 1, pp. 16-21, 1997.

[64] B. B. Lundberg, V. Risovic, M. Ramaswamy, and K. M. Wasan, "A lipophilic paclitaxel derivative incorporated in a lipid emulsion for parenteral administration," Journal of Controlled Release, vol. 86, no. 1, pp. 93-100, 2003.

[65] M. Yokoyama, M. Miyauchi, N. Yamada et al., "Characterization and anticancer activity of the micelle-forming polymeric anticancer drug Adriamycin-conjugated poly(ethylene glycol)-poly(aspartic acid) block copolymer," Cancer Research, vol. 50, no. 6, pp. 1693-1700, 1990. 
[66] K. Kataoka, G. S. Kwon, M. Yokoyama, T. Okano, and Y. Sakurai, "Block copolymer micelles as vehicles for drug delivery," Journal of Controlled Release, vol. 24, no. 1-3, pp. 119-132, 1993.

[67] M. Ramaswamy, X. Zhang, H. M. Burt, and K. M. Wasan, "Human plasma distribution of free paclitaxel and paclitaxel associated with diblock copolymers," Journal of Pharmaceutical Sciences, vol. 86, no. 4, pp. 460-464, 1997.

[68] X. Zhang, H. M. Burt, D. Von Hoff et al., "An investigation of the antitumour activity and biodistribution of polymeric micellar paclitaxel," Cancer Chemotherapy and Pharmacology, vol. 40, no. 1, pp. 81-86, 1997.

[69] X. Zhang, H. M. Burt, G. Mangold et al., "Anti-tumor efficacy and biodistribution of intravenous polymeric micellar paclitaxel," Anti-Cancer Drugs, vol. 8, no. 7, pp. 696-701, 1997.

[70] A. Miwa, A. Ishibe, M. Nakano et al., "Development of novel chitosan derivatives as micellar carriers of taxol," Pharmaceutical Research, vol. 15, no. 12, pp. 1844-1850, 1998.

[71] J. D. Jonkman-de Vries, K. P. Flora, A. Bult, and J. H. Beijnen, "Pharmaceutical development of (investigational) anticancer agents for parenteral use-A review," Drug Development and Industrial Pharmacy, vol. 22, no. 6, pp. 475-494, 1996.

[72] G. L. Flynn, "Solubility concepts and their applications to the formulation of pharmaceutical systems," Journal of Parenteral Science and Technology, vol. 38, no. 5, pp. 202-209, 1984.

[73] B. D. Tarr and S. H. Yalkowsky, "A new parenteral vehicle for the adminstration of some poorly water soluble anti-cancer drugs," Journal of Parenteral Science and Technology, vol. 41, no. 1, pp. 31-33, 1987.

[74] J. Szejtli, “Cyclodextrins in drug formulations," Pharmaceutical Technology, pp. 16-24, 1991.

[75] U. S. Sharma, S. V. Balasubbamanian, and R. M. Straubinger, "Pharmaceutical and physical properties of paclitaxel (Taxol) complexes with cyclodextrins," Journal of Pharmaceutical Sciences, vol. 84, no. 10, pp. 1223-1230, 1995.

[76] T. Cserhati, E. Forgacs, and J. Hollo, "Interaction of taxol and other anticancer drugs with alpha-cyclodextrin," Journal of Pharmaceutical and Biomedical Analysis, vol. 13, pp. 533-541, 1995.

[77] W. Mellado, N. F. Magri, D. G. I. Kingston, R. Garcia-Arenas, G. A. Orr, and S. B. Horwitz, "Preparation and biological activity of taxol acetates," Biochemical and Biophysical Research Communications, vol. 124, no. 2, pp. 329-336, 1984.

[78] B. Nuijen, M. Bouma, J. H. M. Schellens, and J. H. Beijnen, "Progress in the development of alternative pharmaceutical formulations of taxanes," Investigational New Drugs, vol. 19, no. 2, pp. 143-153, 2001.

[79] D. M. Vyas, H. Wong, A. R. Crosswell et al., "Synthesis and antitumor evaluation of water soluble taxol phosphates," Bioorganic and Medicinal Chemistry Letters, vol. 3, no. 6, pp. 1357-1360, 1993.

[80] Y. Ueda, A. B. Mikkilineni, J. O. Knipe, W. C. Rose, A. M. Casazza, and D. M. Vyas, "Novel water soluble phosphate prodrugs of taxol possessing in vivo antitumor activity," Bioorganic and Medicinal Chemistry Letters, vol. 3, no. 8, pp. 1761-1766, 1993.

[81] C. Li, D. Yu, T. Inoue et al., "Synthesis and evaluation of watersoluble polyethylene glycol-paclitaxel conjugate as a paclitaxel prodrug," Anti-Cancer Drugs, vol. 7, no. 6, pp. 642-648, 1996.

[82] A. Pendri, C. D. Conover, and R. B. Greenwald, "Antitumor activity of paclitaxel-2'-glycinate conjugated to poly(ethylene glycol): a water-soluble prodrug," Anti-Cancer Drug Design, vol. 13 , no. 5, pp. 387-395, 1998.
[83] F. Dosio, P. Brusa, P. Crosasso, S. Arpicco, and L. Cattel, "Preparation, characterization and properties in vitro and in vivo of a paclitaxel-albumin conjugate," Journal of Controlled Release, vol. 47, no. 3, pp. 293-304, 1997.

[84] E. Presenti, C. Franzetti, and G. Biasoli, "Synthesis and biological activity of water soluble polymer-bound taxol derivatives," Proceedings of the American Association for Cancer Research, vol. 36, article 307, 1995.

[85] A. W. Heldman, L. Cheng, G. M. Jenkins et al., "Paclitaxel stent coating inhibits neointimal hyperplasia at 4 weeks in a porcine model of coronary restenosis," Circulation, vol. 103, no. 18, pp. 2289-2295, 2001.

[86] P. W. Serruys, P. De Jaegere, F. Kiemeneij et al., "A comparison of balloon-expandable-stent implantation with balloon angioplasty in patients with coronary artery disease," The New England Journal of Medicine, vol. 331, no. 8, pp. 489-495, 1994.

[87] E. S. Park, M. Maniar, and J. C. Shah, "Biodegradable polyanhydride devices of cefazolin sodium, bupivacaine, and taxol for local drug delivery: preparation, and kinetics and mechanism of in vitro release," Journal of Controlled Release, vol. 52, no. 1-2, pp. 179-189, 1998.

[88] M. P. Wu, J. A. Tamada, H. Brem, and R. Langer, "In vivo versus in vitro degradation of controlled release polymers for intracranial surgical therapy," Journal of Biomedical Materials Research, vol. 28, no. 3, pp. 387-395, 1994.

[89] C. I. Winternitz, J. K. Jackson, A. M. Oktaba, and H. M. Burt, "Development of a polymeric surgical paste formulation for taxol," Pharmaceutical Research, vol. 13, no. 3, pp. 368-375, 1996. 

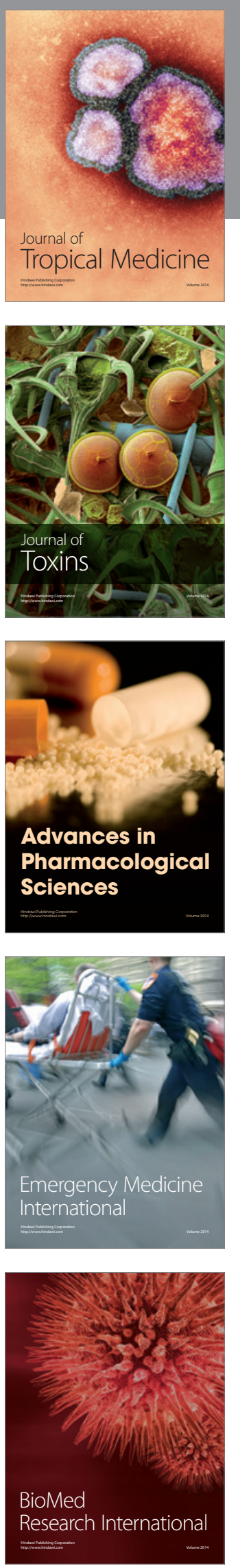
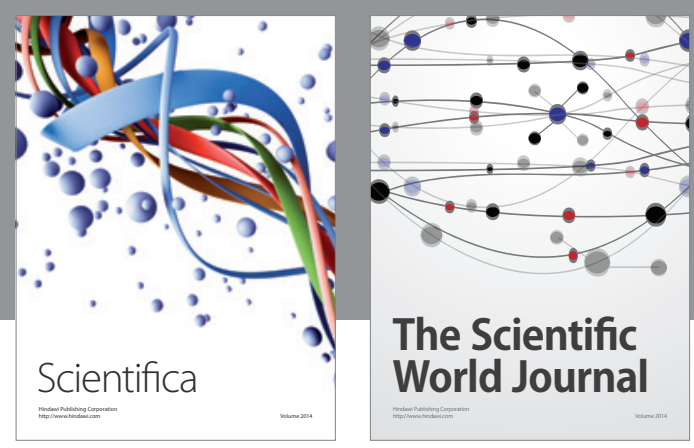

The Scientific World Journal
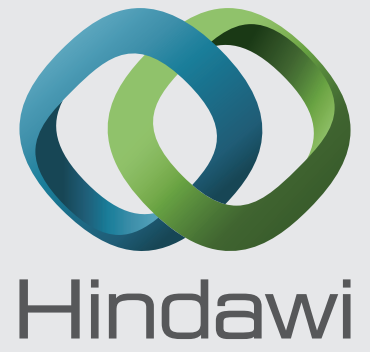

Submit your manuscripts at

http://www.hindawi.com
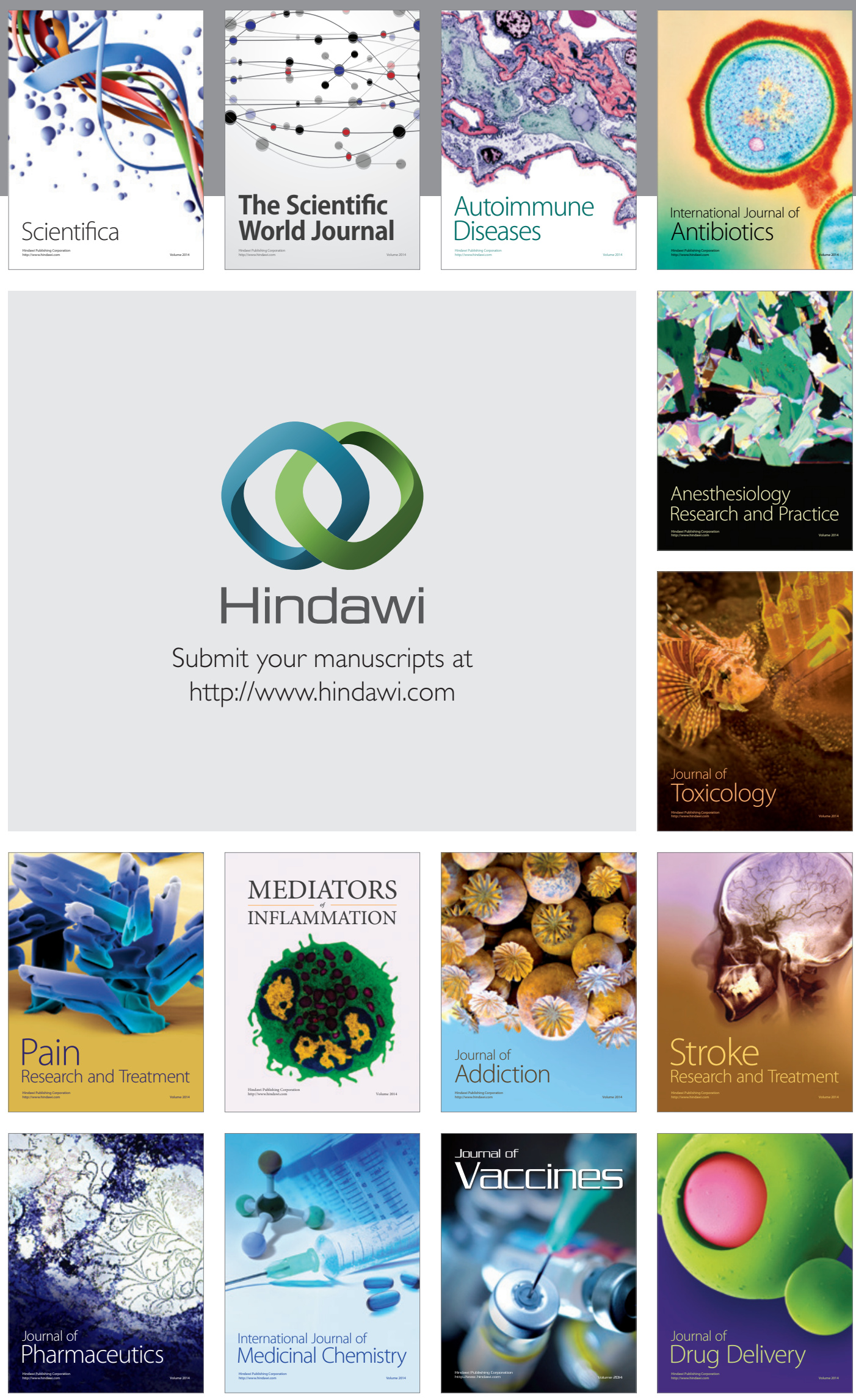